\title{
¿Cómo avanzar la participación en el continente más desigual de todos?
}

\author{
Bernardo KliksberG*
}

\section{1. ¿Participación, consenso o moda?}

En los 12 procesos electorales que han culminado o se están desarrollando en América Latina entre noviembre 2005 y diciembre del 2006, virtualmente todos los candidatos con posibilidades, han prometido más participación a la ciudadanía, y se han esmerado en incluir el tema con toda frecuencia en sus discursos, y sus programas de gobierno. Ello va desde propuestas muy elaboradas e integrales como la de la nueva presidenta de Chile, Michelle Bachelet, que ha prometido trabajar por un "Gobierno Ciudadano", hasta los ofrecimientos de más información y transparencia.

Tras este aparente consenso hay realidades muy concretas. La presión de la ciudadanía de la región por participación crece todos los días. Se expresa en las encuestas donde los gestos autoritarios, o la falta de comunicación, son inmediatamente registrados en bajas de popularidad, hasta las protestas masivas, cuando la distancia entre las promesas de los gobiernos, y las realidades son relevantes, o las necesidades no atendidas de gran envergadura.

Sin embargo, con avances significativos, sigue existiendo un retraso importante entre el aparente consenso del liderazgo político, y la ciudadanía sobre la participación, y los hechos. Las intenciones participatorias encuentran en el camino obstáculos importantes, y resistencias considerables.

Ello reafirma continuamente las múltiples frustraciones que la ciudadanía ha tenido con grandes anuncios participatorios que se transformaron después en prácticas clientelares o intentos manipulatorios.

Por ende cabe plantearse si el nuevo impulso a la participación de inicios del siglo XXI tendrá sólo el significado de moda transitoria, o si empiezan a

\footnotetext{
* Asesor principal del Pnud para América Latina. Doctor honoris causa de numerosas universidades. Dirección: Inter-American Development Bank - 1300 New York Ave., NW, NW400, Washington, DC, 20577, EUA. E-mail: bernardok@Contractual.iadb.org.
} 
aparecer las precondiciones necesarias para que la participación se instale solidamente en el contexto histórico latinoamericano.

Este artículo tratará de dar respuesta a esta pregunta central. Explorar este interrogante, e identificar condiciones favorables a la participación, puede aportar al debate a fondo sobre el tema, y sumar elementos para la elaboración de políticas orgánicas que potencien esas condiciones.

Para cumplir estos objetivos, el artículo procurará en primer lugar poner a foco algunas de las principales tendencias de cambio que se observan actualmente en el contexto de la región.

En segundo lugar, tratará de mostrar el rol particular que puede cumplir la participación en sociedades tan desiguales como las latinoamericanas. En tercer término, reseñará y extraerá lecciones de experiencias participatorias ejemplares de la región. A continuación, identificará obstáculos y resistencias. Finalmente en base a todo lo anterior, señalará algunos prerrequisitos para una participación efectiva en la región, y reflexionará sobre sus perspectivas.

\section{El nuevo contexto latinoamericano}

En el último quinquenio el continente viene experimentando cambios de gran significación que están modificando aspectos sustanciales del perfil de sociedad heredado de las décadas de los 1980 y 90.

Avanzan fuertemente los procesos de democratización. Sociedades civiles cada vez más activas y articuladas están exigiendo una reforma del sistema político, y del Estado de nuevo cuno.

Quieren sistemas electorales que den plena garantía al ciudadano, y que le permitan un rol más activo. Presionan por mejorar la representatividad de los liderazgos políticos, y por el establecimiento de canales por los que rindan cuenta continua.

Impulsan un nuevo perfil de Estado, volcado en la gran deuda social de la región, descentralizado hacia las regiones y los municipios, transparente, gestionado profesionalmente, con un servicio civil de carrera, con instancias de todo orden de control, combate activo a la corrupción, y con amplios espacios para la participación.

La visión de la ciudadanía está superando numerosas falacias derivadas del pensamiento economicista ultra ortodoxo predominante en las dos décadas anteriores. La idea de que había que prescindir del Estado, minimizarlo y confiar todo en el mercado, está dejando lugar a una concepción que apunta a una alianza entre un Estado capaz, y con sensibilidad social, empresas socialmente responsables, y una sociedad civil plenamente movilizada.

Por otra parte las nuevas y vigorosas demandas tienen una de sus bases de sustentación en vigorosos procesos de fortalecimiento de la sociedad civil. 
Crecen las organizaciones constituidas desde abajo por iniciativa de los ciudadanos. Está aumentando el interés entre las nuevas generaciones por formar parte dichas organizaciones. Según estima el Instituto de Servicio Global de la Universidad Washington, St. Louis (2004), hay actualmente en la región no menos de un millón de organizaciones de la sociedad civil (OSC). Los principales campos en los que actúan son: desarrollo comunitario, educación y capacitación, participación cívica, salud, necesidades básicas, medio ambiente, derechos humanos, procesos de paz y servicios de emergencia.

Según los estimados de la Universidad Johns Hopkins en países como Argentina y Brasil las OSC generan entre el 2\% y el 3\% del producto bruto anual. Ilustra su afirmación en la sociedad, el hecho de que en la región en lugar de llamarse organizaciones no gubernamentales, se ha cambiado esa definición que es por negación, lo que no son, por otra asertiva, organizaciones de la sociedad civil (OSC).

Uno de los tantos campos en donde han crecido las OSC es el de la presión sobre los poderes públicos por información. Cunill (2006) da cuenta precisa de los avances:

Existen observatorios ciudadanos que publican en la prensa interrogantes dirigidos a las autoridades con el propósito de propiciar el rendimiento de cuentas en torno a las políticas públicas (vg. Observatorio Ciudadano de la Educación, México), o a los resultados del análisis de la gestión municipal (vg. Laboratorio de Observación de la Gestión Urbana, LOGU, en Cali, Colombia). Incluso, hay ONGs (vg. Transparencia en la Administración de los Estados, Argentina) que están desarrollando sistemas para el seguimiento de las contrataciones del Estado por Internet. Comienzan a operar, además, agrupaciones de ONGs en pos de la transparencia gubernamental (vg. Foro Social para la Transparencia, en Argentina) y movimientos gremiales con este mismo propósito (vg. Movimiento en Defesa da Etica e Eficacia do Fisco Paulista, en Brasil). Transparencia Internacional y el Proyecto Responsabilidad Anti-Corrupción en las Américas constituyen, a su vez, ejemplos de acciones de amplio alcance de monitoreo efectuado por la sociedad civil, con apoyo de agencias internacionales.

Al mismo tiempo que se han desenvuelto estos esperanzadores y positivos desarrollos en materia de democratización, las economías latinoamericanas han tenido buenas tasas de crecimiento en los dos últimos años. El producto bruto creció en el 2004 en un 5,9\%, en el 2005 en un 4,3\%, y se anticipa en el 2006 , un aumento del 4,1\%. La región se ha visto favorecida entre otros aspectos por la activación de las economías desarrolladas, y de la economía mundi- 
al, aumentos importantes en los precios de las materias primas que exporta, y el impacto de China en la demanda.

También la han beneficiado sobremanera las remesas migratorias aporte que no se hallaba previsto en las proyecciones económicas convencionales. La explosión migratoria que llevo a más de 10 millones de latinoamericanos en los últimos 10 años a pasar a vivir en EEUU, y otros países desarrollados generó un fenómeno muy especial. Envían anualmente a sus familias en sus países de origen, 200 a 300 dólares ocho veces por año. Ello sumó en el 2004, 45 mil millones de dólares, en el 2005, 55 mil y se prevé llegue en el 2006, a 60 mil millones. Es la principal fuente de ingresos de divisas, superando los préstamos, y la cooperación internacional.

Significan del 15\% al 30\% del producto bruto en países como El Salvador, Nicaragua, Honduras, República Dominicana, Guatemala, Haití, y otros. Aun en economías tan poderosas como la de México constituyen la segunda fuente de ingresos después del petróleo.

Sin embargo, no obstante estos avances políticos y económicos, y de su excepcional potencial de recursos naturales (materias primas estratégicas, fuentes de energía barata, 30\% de las aguas puras del planeta, grandes posibilidades agropecuarias etc.), América Latina presenta agudos problemas sociales.

Los altos niveles de pobreza y pobreza extrema han permanecido estacionados. No han descendido significativamente a pesar incluso del crecimiento económico de los últimos años, como puede observarse a continuación.

$$
\text { Ilustración } 1
$$

Pobreza y pobreza extrema en América Latina (1980-2005)

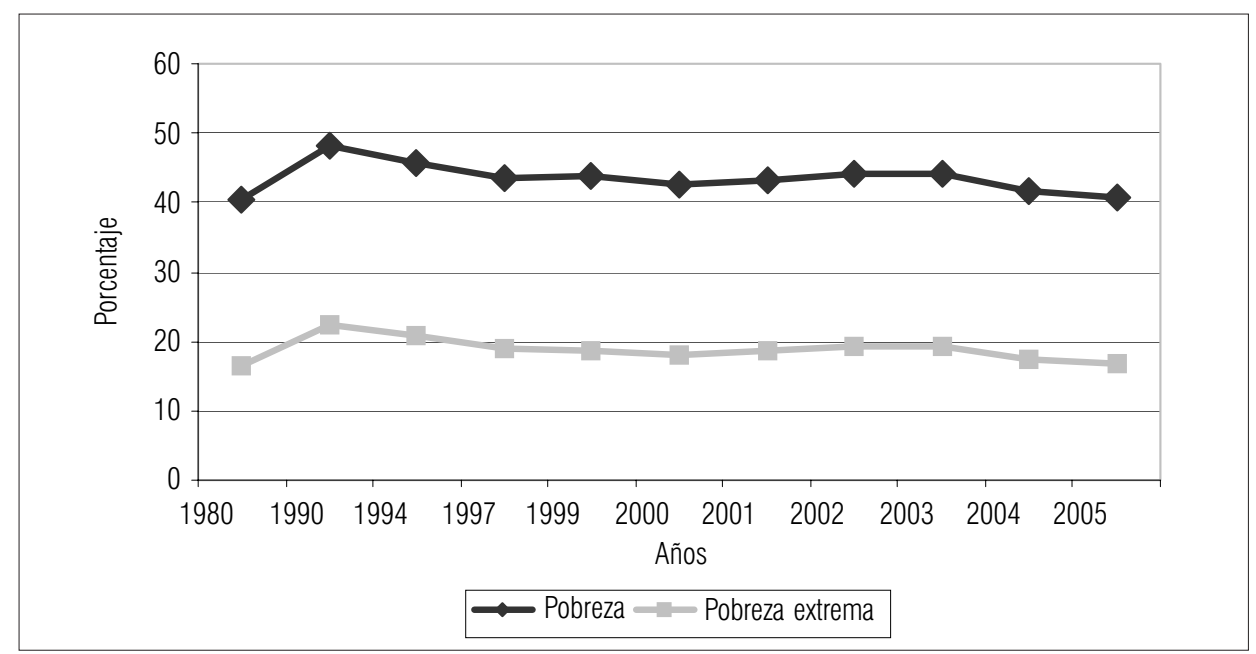

Fuente: Cepal. Panorama social de América Latina. 1996-2005. 
Como se observa en los últimos 25 años, ambas curvas la de pobreza y la de pobreza extrema están estancadas. Como la población creció ello implica que el numero de pobres y pobres extremos aumento. Efectivamente están son las cifras.

\begin{tabular}{|c|c|c|c|c|}
\hline \multicolumn{5}{|c|}{$\begin{array}{l}\text { Evolución de la pobreza en América Latina - 1980-2005 } \\
\text { (porcentaje de la población) }\end{array}$} \\
\hline \multirow[b]{2}{*}{ Año } & \multicolumn{2}{|c|}{ Pobreza extrema } & \multicolumn{2}{|c|}{ Pobreza total } \\
\hline & $\begin{array}{c}\% \text { de la } \\
\text { población }\end{array}$ & $\begin{array}{l}\text { № de personas } \\
\text { (en miles) }\end{array}$ & $\begin{array}{c}\% \text { de la } \\
\text { población }\end{array}$ & $\begin{array}{c}\text { № de personas } \\
\text { (en miles) }\end{array}$ \\
\hline 1980 & 16,6 & 60.127 & 40,5 & 146.695 \\
\hline 2000 & 18,1 & 94.650 & 42,5 & 222.245 \\
\hline 2001 & 18,5 & 98.177 & 43,3 & 229.787 \\
\hline 2002 & 19,4 & 104.450 & 44 & 236.897 \\
\hline 2003 & 19,2 & 104.847 & 44,3 & 241.914 \\
\hline 2004 & 17,4 & 96.348 & 41,7 & 230.904 \\
\hline 2005 & 16,8 & 94.306 & 40,6 & 227.906 \\
\hline
\end{tabular}

Fuente: Cepal. Panorama social de América Latina. 1996-2005.

En 1980 había 146 millones de pobres en América Latina, entre ellos 60 millones de pobres extremos. En el 2005, los pobres eran 228 millones y los pobres extremos 94 millones.

Estas cifras se reflejan en los profundos atrasos de la región en cuanto a conseguir las metas del milenio en áreas claves como reducción de la pobreza extrema, mortalidad materna, finalización de escuela primaria, saneamiento y sostenibilidad del medio ambiente.

Los costos de estos altísimos niveles de exclusión social son muy altos en términos de perdida de la cohesión social, y tensión al interior de las sociedades. Chocan directamente con una democratización cada vez más incluyente, movilizada por las luchas ciudadanas, y niveles de pobreza que no condicen con el potencial económico de la región, y tampoco con su producto bruto per capita.

Este "volcán social latente" ha estado detrás del hecho de que 14 presidentes latinoamericanos han debido dejar su cargo antes del tiempo fijado desde 1993. Los procesos fueron diversos y propios de cada país, pero en general no han sido expulsados por golpes militares, sino por amplias protestas de la sociedad civil. 
Tras ellas una fuerza impulsora central fue el sentimiento de que estaban defraudando sus promesas, e incumpliendo con garantizar las necesidades básicas.

Al mismo tiempo la búsqueda afanosa por la población de alternativas políticas que le aseguren respuestas en estos planos básicos, ha dado lugar al pronunciado giro político en muchos países de vastos sectores hacia gobiernos con fuerte perfil de reformismo social a favor de los pobres. Los partidos políticos tradicionales han sido desplazados en diversos casos por esta nueva ola de partidos o movimientos alternativos.

La región se mueve en ese contexto de más democracia, mejor macroeconomía, y estancamiento social agudo, con altas tensiones políticas, y fuertes márgenes de ingobernabilidad democrática, y un giro político pronunciado hacia gobiernos de fuerte corte social.

Pero falta incluir en el cuadro un factor fundamental, esencial para entender el papel particular que esta región puede cumplir el desarrollo de la participación, se trata de la desigualdad.

\section{El papel de la participación en la región más desigual del planeta}

¿Cómo se explica que un continente con condiciones naturales tan privilegiadas como las de América Latina tenga una pobreza persistente de tanta profundidad?

¿Cómo se explica que en América Latina a pesar de crecer la economía la pobreza se reduce muy poco, y en algunos países la pobreza se ha demostrado casi inelástica ante el crecimiento? ¿Cómo se explica la discrepancia entre el producto bruto per capita de la región y sus niveles de pobreza propios de regiones con un producto per capita mucho menor?

Una de las causas centrales de esta "pobreza persistente y paradojal" está en las pronunciadas desigualdades que cruzan todos los aspectos de las estructuras económicas y sociales de la región.

América Latina es efectivamente la región más desigual del planeta. Mientras los coeficientes Gini de distribución del ingreso son de 0,25 a 0,30 en los países nórdicos, en América Latina los duplican, son en su mayoría de 0,50 a 0,60 .

El siguiente tabla refleja las disparidades de la región, en relación con países como Italia y USA que es el más desigual de los desarrollados. 


\begin{tabular}{|c|c|c|c|c|}
\hline \multicolumn{5}{|c|}{$\begin{array}{c}\text { Tabla } 2 \\
\text { Indicadores de desigualdad para algunos de los países de } \\
\text { América Latina, Estados Unidos e Italia }\end{array}$} \\
\hline País & $\begin{array}{l}\text { Coeficiente } \\
\text { Gini }\end{array}$ & $\begin{array}{l}\text { Porcentaje del } \\
10 \% \text { superior en } \\
\text { el ingreso total }\end{array}$ & $\begin{array}{l}\text { Porcentaje del } \\
10 \% \text { inferior en } \\
\text { el ingreso total }\end{array}$ & $\begin{array}{l}\text { Relación entre los } \\
\text { ingresos del décimo } \\
\text { decil y el primer decil }\end{array}$ \\
\hline Brasil (2001) & 59,0 & $47,2 \%$ & $2,6 \%$ & 54,4 \\
\hline Colombia (1999) & 57,6 & $46,5 \%$ & $2,7 \%$ & 57,8 \\
\hline Chile (2000) & 57,1 & $47,0 \%$ & $3,4 \%$ & 40,6 \\
\hline México (2000) & 54,6 & $43,1 \%$ & $3,1 \%$ & 45,0 \\
\hline Argentina (2000) & 52,2 & $38,9 \%$ & $3,1 \%$ & 39,1 \\
\hline Jamaica (1999) & 52,0 & $40,1 \%$ & $3,4 \%$ & 36,5 \\
\hline República Dominicana (1997) & 49,7 & $38,6 \%$ & $4,0 \%$ & 28,4 \\
\hline Uruguay (2000) & 44,6 & $33,5 \%$ & $4,8 \%$ & 18,9 \\
\hline Estados Unidos (1997) & 40,8 & $30,5 \%$ & $5,2 \%$ & 16,9 \\
\hline Italia (1998) & 36,0 & $27,4 \%$ & $6,0 \%$ & 14,4 \\
\hline Costa Rica (2000) & $48,8^{*}$ & $34,8 \%$ & $4,2 \%$ & 25,1 \\
\hline El Salvador (2002) & 52,5 & & & \\
\hline Guatemala (2000) & $54,2^{*}$ & $46,8 \%$ & $2,4 \%$ & 63,3 \\
\hline Honduras (2002) & 58,8 & & & \\
\hline Nicaragua & 57,9 & & & \\
\hline Panamá & 51,5 & & & \\
\hline
\end{tabular}

Mientras que las distancias entre el $10 \%$ más rico y el $10 \%$ más pobre eran en Italia de 14 a 1 , y en USA de 17 a 1, llegaban a 54 a 1 en Brasil, 59 a 1 en Colombia, y 63 a 1 en Guatemala.

Las desigualdades no se dan sólo en los ingresos, recorren todas las áreas. Son aun mayores en el acceso a uno de los principales activos, la tierra, como puede apreciarse a continuación.

\section{Tabla 3}

\section{Coeficientes Gini de distribución de la tierra en América Latina}

\begin{tabular}{lccc}
\hline \multirow{2}{*}{ País } & \multicolumn{2}{c}{ Deiniger e Olinto } & Pnud \\
\cline { 2 - 3 } & $1950-79$ (i) & $1980-90$ (ii) & 1981(iii) \\
\hline Antigua & 0,74 & & \\
Argentina & 0,86 & 0,85 & \\
Bahamas & 0,90 & 0,87 & \\
Barbados & 0,90 & 0,93 & \\
Belice & 0,72 & 0,71 & \\
Bolivia & & 0,77 & \\
\hline
\end{tabular}




\begin{tabular}{|c|c|c|c|}
\hline \multirow{2}{*}{ País } & \multicolumn{2}{|c|}{ Deiniger e Olinto } & \multirow{2}{*}{$\begin{array}{c}\text { Pnud } \\
1981(\text { iii) }\end{array}$} \\
\hline & 1950-79(i) & $1980-90$ (ii) & \\
\hline Brasil & 0,83 & 0,85 & 0,86 \\
\hline Colombia & 0,85 & 0,77 & 0,70 \\
\hline Costa Rica & 0,81 & & \\
\hline Chile & & & 0,64 \\
\hline República Dominicana & 0,80 & & 0,70 \\
\hline Ecuador & 0,86 & & 0,69 \\
\hline El Salvador & 0,83 & & \\
\hline Grenada & 0,78 & 0,74 & 0,69 \\
\hline Guatemala & 0,86 & & \\
\hline Guyana & & 0,68 & \\
\hline Honduras & 0,75 & & 0,64 \\
\hline Jamaica & 0,81 & 0,81 & \\
\hline México & 0,59 & & \\
\hline Nicaragua & 0,80 & & \\
\hline Panamá & 0,71 & 0,87 & 0,84 \\
\hline Paraguay & 0,86 & 0,78 & 0,94 \\
\hline Perú & 0,94 & & 0,61 \\
\hline Puerto Rico & 0,73 & 0,77 & \\
\hline Suriname & 0,73 & & \\
\hline Trinidad y Tobago & 0,68 & & \\
\hline Uruguay & 0,82 & 0,80 & 0,84 \\
\hline Venezuela & 0,92 & & \\
\hline \multicolumn{4}{|c|}{$\begin{array}{l}\text { Fuentes: Cálculos basados en Deininger y Olinto (2002) y Pnud (1993). } \\
\text { Nota: Los valores para cada país corresponden en la columna (i) al primer valor en el periodo 1950-79 y en la } \\
\text { columna (ii) a la más reciente observación durante el periodo 1980-94. }\end{array}$} \\
\hline
\end{tabular}

Los coeficientes Gini de distribución de la tierra son mucho peores que los de ingresos. Mientras que el anterior es de 0,59, el Gini de la tierra es de 0,81.

Es mucho más elevado que el del Sudeste Asiático, 0,56, y el de Europa Occidental 0,57.

Con progresos el acceso a educación y salud es asimismo muy desigual. La región ha alcanzado más de un $90 \%$ de matriculación en escuela primaria, pero a consecuencia de la pobreza, la desarticulación familiar (en la que la pobreza incide fuertemente), y la gran amplitud del trabajo infantil, sólo se gradúa en secundaria un $40 \%$. En el $20 \%$ más pobre la cifra baja mucho más, sólo es el 12\%. El 88\% de los estudiantes pobres deserta antes de terminar la escuela primaria o la secundaria. La deserción primaria es 14 veces mayor en el $20 \%$ más pobre que en el más rico.

En la población indígena, 40 millones, la disparidad es mucho mayor.

Así en Guatemala donde más del $60 \%$ de la población es indígena, el analfabetismo es en la población no indígena del $20 \%$ y en la indígena del $48 \%$.

También es dispar el acceso a educación de la población de color.

En Brasil uno de cada diez jóvenes blancos termina la universidad. En cambio la finaliza uno de cada 50 afroamericanos. 
Con avances en los promedios generales, las disparidades en salud son muy marcadas. La mortalidad infantil es cinco veces mayor en el $20 \%$ más pobre que en el más rico en Bolivia, y Perú, tres veces mayor en Brasil, República Dominicana, Paraguay y Guatemala. La mortalidad materna indígena en México es tres veces mayor que la elevada mortalidad materna promedio.

A las desigualdades anteriores se suma la inequidad en el acceso al crédito. El 95\% de las empresas son pequeñas y medianas, y generan gran parte del empleo, 160 millones de trabajos, pero solo reciben el 5\% del crédito que otorga el sistema financiero.

Son muy marcadas las desigualdades según el lugar de residencia. Los indicadores de pobreza extrema las evidencian claramente. Véase las diferencias en las tasas de indigencia entre población urbana y rural.

\begin{tabular}{|c|c|c|c|c|c|c|}
\hline \multicolumn{7}{|c|}{ 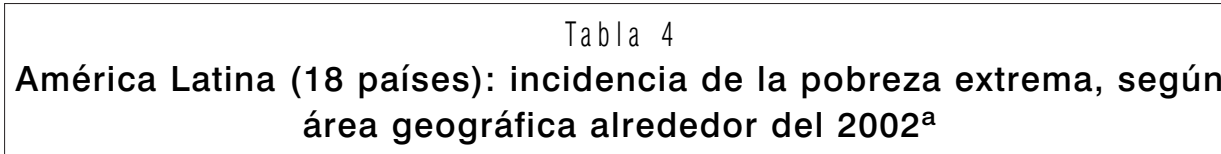 } \\
\hline \multirow[t]{2}{*}{ País } & \multirow[t]{2}{*}{$\begin{array}{l}\text { Porcentaje de } \\
\text { población urbana }\end{array}$} & \multicolumn{2}{|c|}{$\begin{array}{c}\text { Tasa de } \\
\text { indigencia }\end{array}$} & \multirow[t]{2}{*}{$\begin{array}{l}\text { Porcentaje de } \\
\text { indigencia rural } \\
\text { /indigencia urbana }\end{array}$} & \multicolumn{2}{|c|}{$\begin{array}{l}\text { Personas indigentes } \\
\text { que vive en el área: }\end{array}$} \\
\hline & & Urbana & Rural & & Urbana & Rural \\
\hline Argentina & 89,6 & 20,9 & - & - & - & - \\
\hline Bolivia & 64,6 & 21,3 & 62,9 & 3,0 & 37,8 & 62,2 \\
\hline Brasil & 79,9 & 10,4 & 28,0 & 2,7 & 63,3 & 36,7 \\
\hline Chile & 85,7 & 4,5 & 6,2 & 1,4 & 78,9 & 21,1 \\
\hline Colombia & 74,5 & 23,7 & - & - & - & - \\
\hline Costa Rica & 50,4 & 5,5 & 12,0 & 2,2 & 34,7 & 65,3 \\
\hline Ecuador & 62,7 & 19,4 & - & - & - & - \\
\hline El Salvador & 55,2 & 14,3 & 33,3 & 2,3 & 36,2 & 63,8 \\
\hline Guatemala & 39,4 & 18,1 & 37,6 & 2,1 & 22,2 & 77,8 \\
\hline Honduras & 48,2 & 36,5 & 69,5 & 1,9 & 33,4 & 66,6 \\
\hline México & 75,4 & 6,9 & 21,9 & 3,2 & 36,7 & 63,3 \\
\hline Nicaragua & 55,3 & 33,2 & 54,9 & 1,7 & 44,1 & 55,9 \\
\hline Panamá & 57,6 & 8,9 & 31,5 & 3,5 & 29,8 & 70,2 \\
\hline Paraguay & 56,1 & 18,4 & 50,3 & 2,7 & 31,5 & 68,5 \\
\hline Perú & 72,3 & 9,9 & 51,3 & 5,2 & 32,4 & 67,6 \\
\hline \multicolumn{7}{|l|}{ República } \\
\hline Dominicana & 65,0 & 17,1 & 26,3 & 1,5 & 55,7 & 44,3 \\
\hline Uruguay & 92,6 & 2,5 & - & - & - & - \\
\hline \multicolumn{7}{|l|}{ Venezuela (Rep. } \\
\hline Bolivariana de) & 87,4 & - & - & - & - & - \\
\hline
\end{tabular}


Las tasas de pobreza extrema rural superan ampliamente las tasas urbanas y alcanzan a más de la mitad de la población en países como Bolivia, Honduras, Nicaragua, Paraguay y Perú.

También la región presencia un rápido crecimiento de una nueva inequidad, la brecha digital. El acceso a la web es muy diferente entre los distintos sectores sociales. En un país como la Argentina por ejemplo de los mas evolucionados en ese plano, según Cepal (2003) en el 7\% más rico de la población accedía a internet el $80 \%$, en el $58 \%$ más pobre sólo el $10 \%$.

Todas las desigualdades anteriores interaccionan reforzándose las unas a las otras y creando círculos perversos de inequidad. Los niños pobres no terminan estudios primarios, luego no consiguen mas que trabajos marginales, y mal pagados, no tienen protección social, y tienden a formar familias que reproducen las condiciones de pobreza iniciales.

Por otra parte las grandes desigualdades congelan la movilidad social, con lo que traen desesperanza e impotencia.

Todo ello tiene a su vez reflejo en términos de participación en la toma de decisiones. Las debilidades socioeconómicas severas significan carencia de información, educación, acceso a redes influyentes, contactos limitados, y llevan a pobreza en poder. Se generan así asimetrías de poder, que refuerzan las socioeconómicas e inversamente.

Ello tiene impactos en múltiples planos.

Son muy sugerentes análisis recientes de la Universidad de Harvard respecto a las correlaciones econométricas entre desigualdad y corrupción. Jon-Sung y Kahagram (2004) estudiaron dichas correlaciones en mas de 100 países y constataron una relación robusta.

Su análisis indica que en sociedades muy polarizadas por la desigualdad amplios sectores tienen limitada información, poca capacidad de organización, y son débiles para monitorear a los grupos minoritarios que concentran los ingresos. En las elites a su vez, este cuadro de poder concentrado con poco control social puede generar incentivos hacia practicas corruptas porque crea una situación de cuasi impunidad.

Ello incidiría en el hecho de que en los países más desiguales la corrupción en los altos niveles es mayor. Muchos países latinoamericanos y africanos son evidencia fuerte de esta hipótesis.

Por otra parte el estudio echa por tierra la hipótesis de que corrupción tiene que ver con Estados grandes, y que se reduciría al minimizar el Estado.

Muestra que por lo contrario la corrupción es mucho menor en Estados fuertes, con políticas públicas activas y una extendida red de servicios a la población. 
Tal es el caso de los países nórdicos. El Estado esta actuando como un gran igualador de oportunidades básicas al asegurar educación, salud, crédito, y otros bienes públicos a todos por igual. Ello crea condiciones para sociedades civiles empoderadas que a su vez van a seguir muy de cerca la acción del Estado, y se crea un juego de poder equilibrado.

En América Latina los agudos niveles de desigualdad instalan dinámicas que llevan a una reproducción continua de la desigualdad. Ella a su vez impide que la pobreza pueda reducirse aun con crecimiento económico.

Lo ha constatado con fuerza un importante informe de la ONU conducido por Ocampo (United Nations, 2005):

La convicción de muchos años de que el crecimiento es la fuerza fundamental para reducir la pobreza es cada vez más cuestionada. Hay una creciente evidencia que el impacto del crecimiento sobre la reducción de la pobreza es significativamente menor cuando la desigualdad aumenta que cuando declina. Por otra parte si el crecimiento contribuye a hacer crecer la desigualdad, la pobreza puede empeorar - si no en términos absolutos, por lo menos en términos relativos, al encontrarse los pobres peor en términos comparativos.

¿Cómo romper esta "trampa de hierro"? Se necesitan políticas públicas muy activas y bien gerenciadas que abran efectivamente oportunidades para todos garantizando salud, educación de buena calidad, acceso a la tierra, apoyen la pequeña y mediana empresa, permitan el acceso a créditos a los microemprendedores, posibiliten la extensión del acceso a internet, y otras semejantes. ${ }^{1}$

La protección universal a la salud debería ser un elemento central porque, además de ser un derecho fundamental, sin ella no hay posibilidad de empleabilidad, ni inserción laboral, ni productividad.

Se necesita asimismo una gran concertación entre Estado, empresas, y sociedad civil, en torno a mejorar la equidad.

En este marco un gran dinamizador de este tipo de políticas y estas concertaciones puede ser la participación.

América Latina tiene hoy bien claro que sus niveles de desigualdad actuales son inadmisibles. Véanse las opiniones sobre el tema.

\footnotetext{
${ }^{1}$ El tema de las políticas necesarias es tratado con detalle en Kliksberg (2004).
} 
Ilustración 2

Percepción de justicia en relación a la distribución del ingreso en América Latina

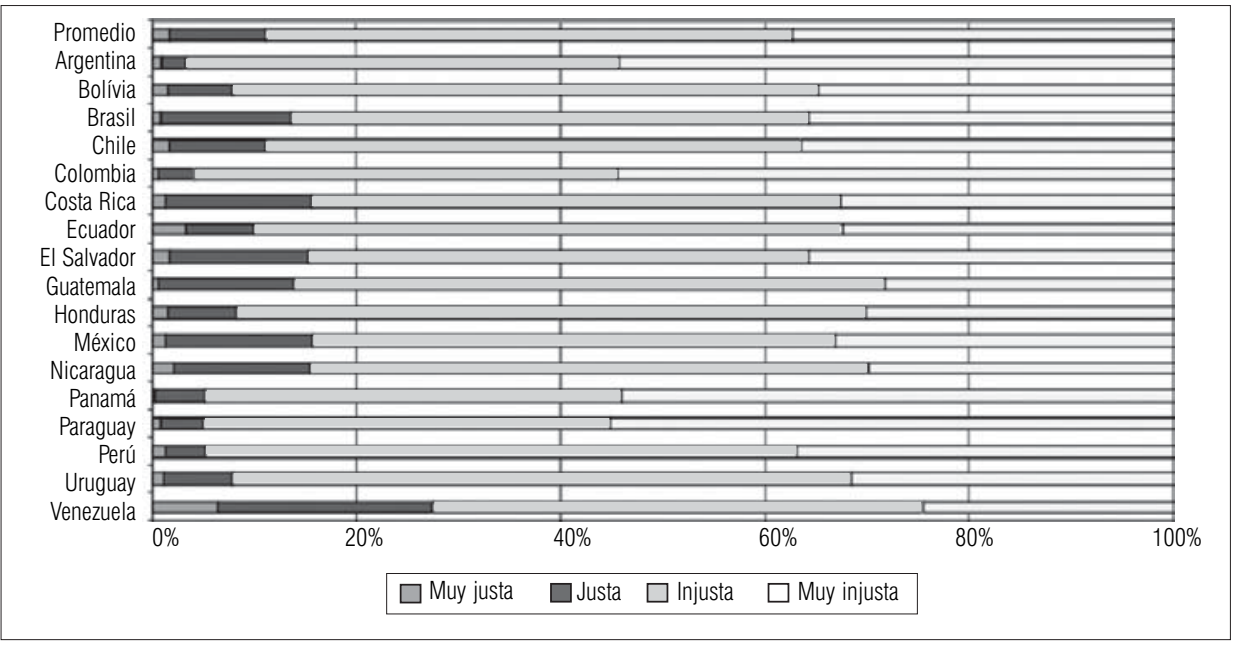

Fuente: LatinBarómetro, 2001.

Para nueve de cada 10 latinoamericanos los niveles de desigualdad actuales son "muy injustos" o "injustos".

En sociedades democráticas la participación en todas las áreas claves aparece como la gran vía para expresar esta disconformidad, y propulsar que la democratización política sea acompañada por una efectiva democratización económica y social.

La participación puede desatar círculos virtuosos en donde a más participación, haya políticas públicas más sensibles, se eleve fuertemente la inversión social, se erradique la corrupción, y ello implique más oportunidades para los más pobres, que a su vez empoderados tendrán mejores condiciones para participar.

Se puede advertir la existencia de correlaciones significativas entre sociedades con gran actividad participatoria, alta equidad, y una inversión social importante, y por el contrario como en América Latina, las inequidades, y la debilidad participatoria, vienen acompañadas de un débil gasto social, que a su vez contribuye a reproducirlas.

Véase la inversión social comparada en diversas regiones. 


\begin{tabular}{|c|c|c|c|c|}
\hline \multicolumn{5}{|c|}{$\begin{array}{c}\text { Tabla } 5 \\
\text { Gastos en seguridad social en el mundo como porcentaje } \\
\text { del producto bruto nacional }\end{array}$} \\
\hline & Pensiones $^{1}$ & Salud $^{2}$ & Otros ${ }^{3}$ & Total del gasto social ${ }^{4}$ \\
\hline África & 1,4 & 1,7 & 1,2 & 4,3 \\
\hline Asia & 3,0 & 2,7 & 0,7 & 6,4 \\
\hline Europa & 12,1 & 6,3 & 6,4 & 24,8 \\
\hline América Latina e Caribe & 2,1 & 2,8 & 3,9 & 8,8 \\
\hline América del Norte & 7,1 & 7,5 & 2,0 & 16,6 \\
\hline Oceanía & 4,9 & 5,6 & 5,6 & 16,1 \\
\hline \multicolumn{5}{|c|}{$\begin{array}{l}\text { Fuente: Tabla 14. Las medias regionales son ponderadas por el producto nacional bruto calculado en función de la paridad de } \\
\text { poder adquisitivo. Ver < www.ilo.org/public/english/protection/socsec/publ/css/table14.html>. }\end{array}$} \\
\hline \multicolumn{5}{|c|}{$\begin{array}{l}1 \text { Gastos cubren pensión de vejez, invalidez, y de sobrevivientes. } \\
{ }^{2} \text { Servicios del cuidado médico cubren servicios de salud. } \\
{ }^{3} \text { Otros gastos cubren accidentes de trabajo, enfermedad, familia, vivienda, y beneficios de asistencia social en efectivo y en } \\
\text { bienes, incluyendo gastos administrativos. } \\
{ }^{4} \text { Total del gasto social cubre pensiones, cuidado médico, y otros aspectos. }\end{array}$} \\
\hline
\end{tabular}

La inversión social europea triplica la de América Latina. La de Oceanía y América del Norte la duplican. En un componente clave como el de salud, el gasto latinoamericano no llega al 3\% del producto bruto. En muchos países no llega al $2 \%$ o lo supera muy poco como puede apreciarse.

\begin{tabular}{|c|c|c|c|c|c|}
\hline \multicolumn{6}{|c|}{$\begin{array}{l}\text { Tabla } 6 \\
\text { Gastos en seguridad social en América Latina y el Caribe en } \\
\text { porcentaje del producto bruto nacional }\end{array}$} \\
\hline \multirow[b]{2}{*}{ País } & \multirow[b]{2}{*}{ Pensiones $^{1}$} & \multirow[b]{2}{*}{ Salud $^{2}$} & \multirow[b]{2}{*}{ Otros $^{3}$} & \multicolumn{2}{|c|}{ Gasto total en seguridad social } \\
\hline & & & & $\begin{array}{l}\text { Porcentaje del producto } \\
\text { bruto nacional }{ }^{4}\end{array}$ & $\begin{array}{l}\text { Porcentaje del gasto } \\
\text { público total }\end{array}$ \\
\hline Argentina & 4,1 & 4,3 & 4,0 & 12,4 & 41,2 \\
\hline Bahamas & - & 2,5 & & - & - \\
\hline Barbados & 4,1 & 4,4 & 1,5 & 9,0 & - \\
\hline Belice & - & 2,1 & & 3,5 & 14,2 \\
\hline Bolivia & - & 2,3 & & 7,0 & 29,3 \\
\hline Brasil & 2,4 & 2,1 & 7,7 & 12,2 & 36,7 \\
\hline Chile & 5,9 & 2,3 & 3,1 & 11,3 & 45,6 \\
\hline Colombia & 0,9 & 5,1 & 0,1 & 6,1 & - \\
\hline Costa Rica & - & 6,8 & & 13,0 & 42,6 \\
\hline
\end{tabular}




\begin{tabular}{|c|c|c|c|c|c|}
\hline \multirow{2}{*}{ País } & \multirow{2}{*}{ Pensiones $^{1}$} & \multirow{2}{*}{ Salud $^{2}$} & \multirow{2}{*}{ Otros $^{3}$} & \multicolumn{2}{|c|}{ Gasto total en seguridad social } \\
\hline & & & & $\begin{array}{l}\text { (Porcentaje del Producto } \\
\text { Bruto Nacional) }{ }^{4}\end{array}$ & $\begin{array}{c}\text { (Porcentaje del gasto } \\
\text { público total) }\end{array}$ \\
\hline Cuba & - & - & & - & - \\
\hline Dominica & 1,4 & 0,4 & 3,0 & 4,8 & - \\
\hline República Dominicana & - & 1,8 & & 2,5 & 15,7 \\
\hline Ecuador & 1,2 & 0,3 & 0,5 & 2,0 & - \\
\hline El Salvador & 1,3 & 1,3 & 1,0 & 3,6 & - \\
\hline Grenada & - & 2,8 & & - & - \\
\hline Guatemala & - & 1,7 & & - & - \\
\hline Guayana & 0,9 & 4,3 & 0,6 & 5,8 & - \\
\hline Jamaica & 0,3 & 2,5 & 1,7 & 4,5 & - \\
\hline México & 0,4 & 2,8 & 0,5 & 3,7 & 22,6 \\
\hline Nicaragua & 1,4 & 4,3 & 3,4 & 9,1 & 28,1 \\
\hline Panamá & 4,3 & 5,6 & 1,4 & 11,3 & 41,3 \\
\hline Perú & - & 2,2 & & - & - \\
\hline Trinidad y Tobago & 0,6 & 2,5 & 3,5 & 6,6 & 22,7 \\
\hline Uruguay & 8,7 & 2,0 & 11,7 & 22,4 & 67,8 \\
\hline Promedio Simple & 2,5 & 2,9 & 2,9 & 8,0 & 34,0 \\
\hline \multicolumn{6}{|c|}{$\begin{array}{l}{ }^{1} \text { Gastos cubren pensión de vejez, invalidez, y de sobrevivientes. } \\
{ }^{2} \text { Servicios del cuidado médico cubren servicios de salud. } \\
{ }^{3} \text { Otros gastos cubren accidentes de trabajo, enfermedad, familia, vivienda, y beneficios de asistencia social en efectivo y en } \\
\text { bienes, incluyendo gastos administrativos. } \\
{ }^{4} \text { Total del gasto social cubre pensiones, cuidado médico, y otros aspectos. }\end{array}$} \\
\hline
\end{tabular}

El reforzamiento de la participación puede presionar por una inversión social a la altura de la brecha social gigantesca de la región. Pero cabe preguntarse: ¿es ello posiblemente fiscalmente?

La presión fiscal de la región es limitada en términos internacionales comparativos. Estas son las cifras.

\begin{tabular}{|lc|}
\hline \multicolumn{2}{|c|}{$\begin{array}{c}\text { Tabla } \\
\text { Presión fiscal, } \mathbf{2 0 0 3}\end{array}$} \\
\hline País & $\begin{array}{r}\text { Ingresos fiscales en porcentaje } \\
\text { del producto bruto interno }\end{array}$ \\
\hline Unión Europea & 40,6 \\
OECD & 36,3 \\
USA & 26,4 \\
América Latina & 16,8 \\
\hline Fuente: Cepal, 2005. & \\
\hline
\end{tabular}

Rap Rio de Janeiro 41(3):537-81, Maio/Jun. 2007 
La presión fiscal latinoamericana es menor de la mitad de la de Unión Europea y de la de los países desarrollados. Consiguientemente los recursos disponibles para políticas públicas democratizadoras son limitados.

A ello se suma el hecho de que el sistema fiscal es agudamente regresivo. Más de la mitad de la recaudación proviene de impuestos al consumo (10\%), sólo una quinta parte $(3,6 \%)$ son impuestos a la renta y el patrimonio, y el resto es carga por seguridad social $(3,2 \%)$. Esta regresividad contribuye a aumentar la desigualdad.

La región tiene como consecuencia Estados con serias limitaciones, y un financiamiento inequitativo de sus recursos.

Entre tantos otros casos, en un país con Guatemala, los ingresos estatales representan 9\% del producto bruto. El país tiene un $48 \%$ de los niños menores de cinco años de edad desnutridos. Se necesita en este caso como en muchos otros una recomposición de los ingresos fiscales, que, junto a su gestión con los mejores criterios gerenciales, pueda enfrentar dramas de esta magnitud. Un paso muy relevante fue la construcción hace dos años a pesar de las restricciones de una Secretaria de Seguridad Alimentaria para encarar la desnutrición.

Las asimetrías de poder y participación se hallan entre las causas de estos reglas de juego fiscales obstructoras de un desarrollo sostenible. Un fortalecimiento a fondo de la participación puede presionar por un nuevo pacto fiscal acorde a las verdaderas prioridades de los países.

En países latinoamericanos donde una ciudadanía empoderada presionó en estas direcciones, se produjeron círculos virtuosos, y logro reducirse la pobreza. En años recientes ello se dio en Chile, y Argentina.

La dictadura militar chilena duplicó la pobreza a pesar de las altas tasas de crecimiento económico. Pasó del $20 \%$ al $40 \%$ de la población. Los gobiernos democráticos apoyados por una ciudadanía muy activa. Se empeñaron en combatirla como prioridad, hicieron nuevos acuerdos fiscales, y recuperaron la inversión en sectores sociales claves, entre ellos educación y salud. Hoy la pobreza es menor al 20\%. La nueva presidenta Michele Bachellet ha indicado que en sus cuatro años de gestión, poniendo en marcha su visión de un gobierno ciudadano basado en participación y respuesta a las prioridades de la gente se propone entre otros proyectos universalizar el acceso a las casas cunas y jardines infantiles, ampliar la cobertura en salud, reformar el sistema de pensiones, y mejorar las villas y los barrios. Su objetivo final es crear un sólido sistema de protección social universal.

El presidente Kirchner inició su gestión en la Argentina con un 58\% de pobreza heredada de las políticas neoliberales rígidas aplicadas en los 90 que triplicaron la pobreza, e hicieron saltar el coeficiente Gini. Las demandas ciudadanas por enfrentar la pobreza como prioridad se expresaron de múltiples 
maneras, la gestión presidencial respondió activamente a ellas, y a su vez la ciudadanía apoyó decididamente las políticas adoptadas. Ellas fueron desde la renegociación de la deuda externa hasta la duplicación de la inversión en educación y salud. Actualmente la pobreza es 31\% y la equidad ha mejorado. Siguen siendo cifras desafiantes pero las mejoras son evidentes.

Costa Rica es el país latinoamericano que ha tenido una verdadera política de Estado en esta materia. Desde la disolución de las fuerzas armadas en 1948, la participación popular masiva ha determinado un proyecto consensuado de inversión en gran escala en educación y salud, a pesar de ser un país pobre en recursos naturales. La equidad es alta, y la pobreza la mitad de la cifra de la región ( $20 \%$ vs.41\%).

En los tres casos la participación ha impulsado y protegido los procesos de cambio, ha equilibrado la sociedad, ha llevado a reducir la pobreza, y en definitiva a conseguir excelentes resultados económicos. Chile mantiene un alto crecimiento económico 6,1 en el 2004 y 6 en el 2005, Argentina es el país que más crece de la región después de Venezuela, 9 en el 2005, y 8,6 en el 2005, y Costa Rica ha logrado conformar un pujante sector de alta tecnología. Ha sido elegida por su estabilidad social y su nivel educativo por inversiones tecnológicas de punta, produce el $22 \%$ de todo el software que sale del continente, y ocupa el tercer lugar mundial en "outsourcing" luego de India y China.

La participación es deseable en cualquier contexto histórico. Cumple finalidades múltiples, para el "desarrollo como ampliación de la libertad" como lo mostró Amartya Sen, pero en el caso especifico de América Latina, la más desigual de todas las regiones, es una llave maestra para que los pueblos recuperen su voz, las sociedades se reequilibren, y se creen condiciones para enfrentar los intolerables niveles de pobreza actuales. ${ }^{2}$

\section{4. ¿La participación es viable en América Latina? Revisión de algunas experiencias que son referencia internacional}

En casi todos los países de la región ha habido experiencias significativas de participación popular en la ultima década. Hemos seleccionado para su

\footnotetext{
${ }^{2}$ Sen (2002) muestra que en realidad es difícil hablar de libertad en condiciones de alta desigualdad. Señala: "La retórica de la libertad ha sido ampliamente utilizada por muchos pensadores que ha demostrado relativamente poco interés por la equidad (...) Sin embargo, resulta difícil entender una perspectiva de libertad que no tenga a la equidad como elemento central. Si la libertad es realmente importante, no puede ser correcto reservarla solamente para unos pocos elegidos (...) La desigualdad es una preocupación central en la perspectiva de la libertad".
} 
comentario tres de ellas que son consideradas unánimemente altamente exitosas, han demostrado sostenibilidad en el tiempo, y han atraído la atención internacional como verdaderos laboratorios de participación cuyas lecciones pueden interesar al mundo entero. Se trata de las experiencias del presupuesto municipal participativo en Porto Alegre, Brasil, de la construcción y gestión de un municipio autogestionario en Villa El Salvador, Perú, y la de excelentes practicas de gobernabilidad y gestión en la Ciudad de Rosario, Argentina.

\section{Porto Alegre. La ciudadanía gestionando el presupuesto}

Iniciada en 1989, la experiencia de presupuesto municipal participativo continúa con pleno vigor en el 2006, y se ha convertido en un hito de referencia obligado a nivel mundial en la materia. Hábitat II de la ONU la escogió como una de las 42 mejores experiencias de gestión urbana del mundo, y el Programa de Gestión de Gestión Urbana de la ONU para América Latina, como una de las 22 mejores practicas de gestión pública.

La ciudad con 1.300.000 habitantes presentaba serios problemas sociales, una población importante viviendo en favelas, y un ambiente muy critico hacia la gestión municipal por sus ineficiencias y episodios de corrupción.

La nueva gestión del Partido de los Trabajadores (PT) decidió lanzar una experiencia pionera, orientada a tratar de generar una nueva relación Estado-sociedad a través de la participación masiva de la ciudadanía en las decisiones sobre la asignación de los recursos para inversiones del municipio.

La intención era promover entre los habitantes la idea de que podían incidir muy fuertemente en la toma de decisiones del municipio, y a través de ello lograr conformar una administración realmente representativa de las mayorías, y cerrar el paso a la cooptación usual de la gestión por intereses particulares.

Como explica Tarso Genro (2005) uno de los creadores de la experiencia y alcalde de la ciudad en el segundo periodo de su implementación:

No se trató simplemente de incentivar la participación popular (...) En realidad fue creado un nuevo centro de decisiones que junto con el Poder Ejecutivo y el Legislativo, democratizaron efectivamente a la acción política e integraron a los ciudadanos comunes en un nuevo "espacio público". Un espacio público no tradicional que le dio potencia al ejercicio de los derechos de la ciudadanía e insto a los ciudadanos a ser más exigentes y críticos.

La voluntad proparticipatoria no quedo en el discurso. Se hizo un muy imaginativo esfuerzo para diseñar mecanismos sustantivos de participación y 
control popular. Se crearon 16 distritos en donde se reunían los ciudadanos de cada uno a decidir las prioridades locales, y cinco comisiones temáticas que discutían prioridades con la visión de los problemas globales de la ciudad. Los participantes elogian sus representantes en el Consejo de Presupuesto Participativo, que llevaría a través de instancias sucesivas sus decisiones al presupuesto final de la ciudad.

Esto implicaba crear todo un espacio público no estatal en que la sociedad cogestionaba el presupuesto. Por otra parte ese mismo espacio era de rendición de cuentas, de cómo se cumplían las decisiones adoptadas en el ejercicio anterior.

El sistema permitía pasar del perfil tecnocrático usual de un presupuesto hecho por la tecnocracia municipal desde sus oficinas, a un presupuesto "vivo" en cuyo proceso de formación intervenían los actores reales.

El presupuesto participativo preveía un calendario anual con diversos ciclos de planificación, discusión e información. Estaba contemplado incluso que los representantes electos por los vecinos para integrar el Consejo de Presupuesto Participativo siguieran un curso de formación sobre presupuesto público para poder cumplir a plenitud con sus responsabilidades.

Los criterios fijados para la toma de decisiones eran progresivos. La asignación de recursos a cada distrito debía estar guiada por su población, los deficits de servicios y de infraestructura en el barrio, y las prioridades temáticas fijadas.

Los primeros años de implementación fueron difíciles. La población acudió masivamente a demandar, y los recursos del municipio eran muy limitados. Se produjo inicialmente un efecto frustración, pero el municipio emprendió una gran reforma tributaria para incrementar su recaudación.

La participación popular en que estaba apoyado le permitió hacerlo con éxito. Allí pudo empezar a concretar las prioridades fijadas por la población al inicio. Ello multiplicó el interés ciudadano y posibilitó profundizar el proceso.

Genro describe:

A partir del final del segundo año de gobierno, el Presupuesto Participativo ya se diseñó como un nuevo hecho político, estructurador de una nueva relación política del Estado con la sociedad en Porto Alegre. Con las obras apareciendo, con la información que circulaba "boca a boca" y también con la información dirigida a través de un programa de TV, orientado por la Coordinación de Comunicación Social de la Alcaldía, las comunidades comenzaron a tener conciencia de que "valía la pena ir al Presupuesto". La ciudad comenzó a tener conciencia de que el gobierno realmente reconocía en sus ciudadanos la fuente de sus decisiones más importantes. "Algo de nuevo", en la manera de gobernar, estaba efectivamente ocurriendo. 
Un rasgo muy especial de la experiencia fue la decisión política de mantener el presupuesto participativo como autónomo, tratando de que el proceso respondiera a la sociedad, y no se convirtiera en una dependencia del municipio.

Otro fue verlo como un proceso abierto a ser perfeccionado permanentemente según los aprendizajes obtenidos en la práctica.

Entre otras modificaciones en el camino se fueron afinando cada vez más los criterios de representatividad para garantizar la legitimidad de los representantes, y dar plena cabida a las nuevas asociaciones de la sociedad civil que nacieran.

La experiencia arrojó resultados de gran significación para todos los actores.

Para la ciudad significó una utilización mucho más optimizante de los recursos limitados. Las evaluaciones indican que la reasignación de recursos en base a las prioridades fijadas a través del proceso participativo, llevaron a un aumento notable de la matricula escolar, el agua potable, el alcantarillado, la pavimentación de áreas pobres, y las facilidades para las pequeñas y medianas empresas.

Para las instituciones municipales el reto de un diálogo permanente con una comunidad movilizada, creó una instancia potente de evaluación del desempeño, de análisis de las rutinas, y un incentivo para la mejora de los procedimientos y las políticas. El control social actuó como un catalizador del mejoramiento de la gestión municipal.

Asimismo la participación masiva de la ciudadanía inhibió o dificultó en extremo las prácticas corruptas, y el clientelismo.

Para los ciudadanos hubo un crecimiento fundamental de su capital social.

Todo ello es muy bien captado en la rigurosa evaluación efectuada por Navarro (1998) para el BID. Señala que:

Los ciudadanos de Porto Alegre han tenido oportunidad de pasar por un proceso plenamente participativo a través de haber:

จ expresado su comprensión de los problemas cruciales que enfrenta la ciudad;

จ establecido prioridades de los problemas que merecen más inmediata atención;

V seleccionado las prioridades y generado soluciones prácticas;

V tenido oportunidad de comparar con las soluciones creadas en otras regiones de la ciudad y en otros grupos de temas; 
$\checkmark$ tomado la decisión definitiva sobre la aprobación, o no, del plan de inversiones; $\mathrm{y}$

- revisado los éxitos y fracasos del programa de inversiones para mejorar sus criterios para el año siguiente.

Todas estas experiencias de los ciudadanos realizados de modo constante dispararon su capital social. Así mejoraron su asociatividad, confianza mutua, civismo, y los valores éticos predominantes. Como resalta la evaluación:

Las mejoras materiales son sin embargo sólo una parte de los beneficios que la ciudad de Porto Alegre experimentó.

El proceso participativo ha tenido también un impacto inconmensurable en la capacidad de los ciudadanos de enfrentar problemas juntos como comunidad, y de trabajar colectivamente para mejorar la calidad de la administración pública y, por consiguiente, la calidad de vida.

También los ciudadanos tuvieron en la experiencia la posibilidad de una buena lectura de cuales pueden ser los límites de experiencias locales. De Souza (1998), uno de los directivos de la experiencia en la gestión Genro explica:

Es preciso comprender que la experiencia del Presupuesto Participativo trasciende al proceso de gestión pública y de planificación democrática. Es también un elemento de toma de conciencia y de despertar a la ciudadanía.

En el transcurso de estos 10 años, la población ha descubierto que hay problemas que no se pueden resolver en el marco de una gestión municipal. Las cuestiones de sanidad, de educación, de vivienda, de protección social, de creación de empleo, de renta etc., dependen, para su resolución estructural, de políticas macroeconómicas y fiscales fijadas al nivel de los estados miembros o del Estado Federal, en las Asambleas Legislativas y en el Congreso Nacional.

De este modo la población ha comprendido que no es suficiente con hacer correcciones en el presupuesto del estado y de la Unión, que hay que atreverse a ir más allá. Es preciso incorporar sus reivindicaciones en luchas más prolongadas para transformar profundamente las estructuras de la sociedad brasileña.

Un nuevo gobierno municipal de otros partidos, surgido de las elecciones del 2004, siguió fortaleciendo el presupuesto participativo, pero puso en marcha junto a el, una reforma del estado y de sus relaciones con la sociedad de muy amplios alcances que denominó: "La gobernanza solidaria local".

La llamó gobernanza porque "está basada en la asociación entre el gobierno y la sociedad para estimular la participación social, y el 
emprendidurismo de los ciudadanos", solidaria porque promueve "la cooperación y la ayuda mutua entre las instituciones gubernamentales y no gubernamentales y las personas", y local porque es una experiencia descentralizada en "regiones, barrios, y villas".

La iniciativa creó nuevos instrumentos entre ellos el Portal de Gestión que ofrece toda la información en línea sobre la gestión de gobierno, el Observatorio de la Ciudad con el mapa barrio por barrio de desigualdades sociales, asociaciones comunitarias, oferta de servicios públicos etc., y el Blog de la Gobernanza espacio interactivo público. Para dar apoyo a todas las iniciativas la ciudad espera capacitar con la Unesco para fines del 2008 a $13 \mathrm{mil}$ agentes voluntarios que actuaran en 82 barrios y 478 villas, y espera tener para fines del 2007, 700 ONGs capacitadas en gestión de proyectos y captación de recursos.

Por otra parte hacia el interior de la administración pública la iniciativa fomenta la intersectorialidad. En cada una de las regiones del Presupuesto Municipal Participativo se han constituido Comités Gestores Locales, donde todos los órganos municipales trabajan integradamente buscando soluciones efectivas.

¿A dónde va la experiencia? Uno de sus principales creadores Cezar Busatto, Secretario de Coordinación Política y Gobernanza local de la ciudad, reflexiona (2006):

No sabemos. Acreditamos que la distribución del poder ejercida con cada vez mas personas, además de ampliar la participación y la libre manifestación de las redes sociales, lleva al perfeccionamiento de las relaciones democráticas. Al incentivar la participación de las personas en la construcción de proyectos de futuro para sus propias comunidades, ellas se emancipan. Sus palabras son oídas, debatidas, sus ideas se amplían, sus propuestas se perfeccionan. Crece su involucramiento, su sentido de pertenencia, su identidad.

\section{Villa El Salvador: la construcción de un municipio autogestionario}

En 1971, 50 mil pobres peruanos en su mayoría llegados de los Andes crearon en un arenal desierto en las afueras de Lima, Villa El Salvador. En la exposición permanente de fotografías de la Villa, puede verse que vivían en carpas, carecían de todo, su suelo era la arena.

Hoy, 2006, Villa El Salvador es una ciudad de 400 mil habitantes, una colmena de actividad agrícola, industrial, comercial y de servicios, con logros 
excepcionales que le han valido algunas de las mayores distinciones mundiales. Recibió el Premio de las Naciones Unidas a la Ciudad Mensajera de la Paz, el premio de la Unesco a la experiencia más desafiante de educación popular, el Premio Príncipe de Asturias a la Concordia, el premio Nacional de Urbanismo del Perú por su diseño humano, y muchos otros. Se suceden los estudios sobre como partiendo de la nada, sin ningún capital físico, ni financiero, y sin ayuda alguna esa comunidad logró metas fundamentales para su población.

A fines de 1981, en solo 18 años, contaba con 50 mil viviendas, el 68\% con materiales nobles. Treinta e ocho mil de ellas fueron construidas por los mismos pobladores. También habían levantado con su esfuerzo 2.800 mil metros cuadrados de calles de tierra afirmada, y construido 60 locales comunales, 64 centros educativos y 32 bibliotecas populares. A ello se sumaban 41 núcleos de servicios integrados de salud, educación y recuperación nutricional, centros de salud comunitarios, una red de farmacias, y una red vial interna con cuatro rutas principales, y avenida pependicuales. Habían plantado medio millón de árboles.

La tasa de matriculación en primaria era el $98 \%$, en secundaria del $90 \%$ cifras mucho mejores a los promedios nacionales. La organización de la comunidad para la salud preventiva, el control de embarazos, y las vacunaciones hizo descender la tasa de mortalidad infantil al 67 por mil frente al 88 al 95 por mil nacional. Después Villa El Salvador había de construir un parque industrial para microempresas, exportar a la Unión Europea, convertirse en la industria de muebles modelo del Perú, y muchos otros logros.

Fue indicativo del proyecto de sociedad que se propusieron los fundadores el hecho de que antes que nada todavía viviendo en las chozas construyeron escuelas para los niños. Michel Azcueta el primer alcalde, y varias veces alcalde narra (Zapata, 1996):

Desde la instalación misma, la población se organizó para que se construyeran escuelas y los niños no perdieran el año escolar. Se formaron 12 comités proescuela en los primeros tres meses y se inició la construcción de muchas aulas en un esfuerzo que, mirado a la distancia, parece enorme y que no se entiende sin acudir a una explicación sobre sus motivaciones subjetivas. Se empezó a dictar clases en aulas que usaban esteras como paredes, las que se impermeabilizaban con plásticos para mínimamente combatir el frío invernal, mientras que el suelo era de tierra apenas afirmada, y los escasos ladrillos fueron reservados para ser usados como precarios bancos por los niños. Estas aulas fueron construidas en jornadas colectivas dominicales, con un entusiasmo y febrilidad que han dejado un recuerdo imborrable entre sus protagonistas. 
En la base de los logros de esta población humilde que se convirtió en un actor histórico decisivo de su propio destino, y en un actor relevante del Perú, se halla la apelación desde el día inicial a la participación popular. En 1973 se creó la Comunidad Urbana Autogestionaria de Villa El Salvador (Cuaves) que había de ser una fuerza esencial en las luchas de la comunidad. Se instalaron 4 mil unidades organizacionales donde todos los pobladores enfrentaban juntos los diversos problemas. Muchísimos miembros de la Villa hicieron experiencias de liderazgo en esa organización abierta. En 1983 se creo la Federación Popular de Mujeres de Villa El Salvador.

Esta línea de trabajo de democracia directa y participación activa acompañó toda la historia de Villa. En el 2001 fue el primer municipio del Perú en incorporar el Presupuesto Municipal Participativo, y llego a asignarle el $35 \%$ de los recursos presupuestarios totales.

La experiencia pasó por diversas etapas, encontró obstáculos, y hubo errores en su gestión en diversos momentos, pero continúa con todo vigor.

Con dificultades enormes, como el hostigamiento de gobiernos que veían en Villa un freno a sus juegos clientelares, o una experiencia conflictiva con las políticas neoliberales, y el ataque de los grupos terroristas que asesinaron a su alcaldesa, a regidores, y líderes, Villa El Salvador ha demostrado una excepcional capacidad de sosteniblidad.

En un país donde el $48 \%$ de la población esta en pobreza, y el $20 \%$ en indigencia, con cifras aun mucho mayores en la población indígena de donde vienen muchos de los fundadores de Villa (68\% de pobreza), la situación de Villa destaca. Se trata de una comunidad dinámica con pobreza pero digna, que cubre las necesidades básicas, garantiza educación y salud, y promueve fuentes de trabajo.

En Villa El Salvador 2006, se entrega un permiso para funcionamiento de una nueva empresa en 24 horas, una partida de nacimiento en 10 minutos. Ha sido declarada Ciudad Productiva, y tiene todo orden de incentivos para las microempresas. Esta estableciendo la Universidad Nacional Tecnológica del Cono Sur para formar productivamente a las nuevas generaciones y alentar los emprendedores. En cada uno de sus colegios, los niños eligen entre ellos alcaldes y regidores escolares. Ellos deciden en consulta con sus representados sobre un presupuesto para inversiones que les asigna el municipio. Este proceso continuo los va formando en prácticas de ciudadanía concretas desde la más temprana edad, y desarrolla sus capacidades para la participación.

El nuevo Plan Integral de Desarrollo al 2021 de Villa basado en un amplio proceso participativo se propone avanzar seis ejes: 1 . educación con equidad y calidad, cultura e identidad, 2. ciudad saludable, 3. desarrollo económico, 
4. modernización de la ciudad, 5. seguridad ciudadana y cultura de paz y

6. democracia participativa y ciudadanía.

Detrás del plan y de toda la gesta del Villa El Salvador, que llevo al papa Juan Pablo II cuando visito Villa el Salvador en 1985 y dio una misa para millones a decir, "en Villa El Salvador hay hambre de D-os", se halla una concepción avanzada del desarrollo.

El nuevo plan se autodescribe del siguiente modo (Villa El Salvador, 2006):

El plan se ubica en la perspectiva del desarrollo humano, es decir, concebimos el desarrollo como un proceso continuo de ampliación de las capacidades y libertad de las personas. En ese sentido, recupera importancia temas de la agenda local, hasta ahora poco atendidos, como la lucha contra la pobreza y violencia familiar. Entender el desarrollo como un proceso de liberación nos pone en ruta de los Objetivos del Milenio propuesto por las Naciones Unidas, y adoptado por el Perú, para reducir la pobreza en el mundo, en los próximos 15 años. Este proceso también, nos ha permitido reafirmar la participación social y la equidad de género, entendida como igualdad de oportunidades y de trato entre mujeres y varones, como ejes transversales del PIDCVES. De igual modo, el Plan se inscribe en el largo proceso de descentralización de Lima Metropolitana y su apuesta por la integración y fortalecimiento de la Asociación de Municipalidades del Área Sur de Lima. En ese sentido, el PIDCVES dialoga con el Plan de Desarrollo de Lima Sur, también en proceso de actualización.

La experiencia de Villa El Salvador donde una población indígena pasa de carpas, a la construcción de un municipio que es referencia mundial, indica claramente que la participación el eje sobre el que se construyó la experiencia, es un constructor formidable de capital social, y que puede ser la fuerza impulsora de esfuerzos humanos de esta envergadura y resultados.

\section{Rosario: un modelo de ciudad incluyente, sostenido, y participativo}

Una gestión municipal renovadora encabezada por los alcaldes Hermes Bimmer y Miguel Lifschitz ha desarrollado en Rosario, la tercera ciudad en población de la Argentina, una experiencia de construcción de una gestión local basada en la participación comunitaria que ha tenido resultados de gran efectividad. El Proyecto Feria de Gobernabilidad Local para América Latina del Programa de las Naciones Unidas para el Desarrollo distinguió en el 2003 a Rosario como 
una de las ciudades mejor gestionadas del continente en base a un amplio numero de parámetros.

La experiencia se inició en los 90 en condiciones muy particulares. La Argentina vivió durante esa década la hegemonía del llamado con frecuencia "pensamiento único". Las recetas económicas ortodoxas dominaron la toma de decisiones públicas, y fueron difundidas intensamente entre la población.

Se llevó adelante un proceso de desplazamiento del Estado de la gran mayoría de sus roles, reducción indiscriminada de su planta de funcionarios, desmantelamiento de numerosos organismos claves, y privatización a ultranza por principio al margen de las contradicciones y complejidades de cada caso. En solo tres años de 1990 a 1992 el número de funcionarios públicos se redujo de 670 mil a 364 mil. A fines de los 90, el gasto público representaba solo el $16,11 \%$ del producto bruto interno.

La ciudad de Rosario con un millón de habitantes, presentaba gravísimos problemas de desocupación, pobreza, exclusión social, y una aguda tensión. El nuevo gobierno municipal liderado por Hermes Binner, dirigente de un partido minoritario en el país (el Partido Socialista), que sólo había ganado la alcaldía en dicha ciudad, emprendió un proyecto que estaba en una dirección totalmente diferente a lo que sucedía a nivel nacional. En lugar de descartar al Estado como actor relevante, y privatizar sus funciones, procuró reformarlo profundamente y convertirlo en un estado municipal orientado a la inclusión social activa, eficiente, con alto nivel de profesionalidad, y totalmente interrelacionado con la ciudadanía a través de formas múltiples de participación popular.

El actual intendente de la ciudad, Miguel Lifschitz, define así las líneas del intento (Rosario, 2005):

Cuando las modas aconsejaban dejar a los individuos librados a su suerte que, la historia demostró, es la peor de las suertes - , desde Rosario decidimos trabajar por el fortalecimiento del Estado, para asegurar los derechos humanos más esenciales. Paralelamente, abrimos las puertas del Estado a los ciudadanos y a las instituciones, dándoles un lugar en el diseño de políticas y en el control creciente sobre el gobierno, para garantizar el pluralismo y la transparencia de la gestión.

En Rosario se construyó paso a paso una institucionalizad renovadora. La de un Estado ligado directamente a las prioridades de los ciudadanos, y cogestionado por ellos.

Entre los instrumentos principales generados estuvieron los siguientes.

Plan Estratégico Local. Producto de amplias consultas e intercambios con las principales organizaciones de la sociedad, estableció la visión de ciudad, y las prioridades para la inversión publico-privada. 
El plan ha sido un instrumento maestro de orientación de las políticas públicas, pero por sobre todo ha sido valiosísima la relación de trabajo conjunto que desencadeno con la sociedad. En lugar de un Estado que planifica de arriba hacia abajo, se creo un equipo en donde la Intendencia lidera un esfuerzo colectivo de gestión de la ciudad en dirección al modelo de ciudad planteado.

El Plan Estratégico Rosario estableció como visión de ciudad la siguiente:

Rosario, una ciudad con oportunidades de vida y de progreso para todos sus habitantes, sustentada en el trabajo y la creación, que recupera el río y se constituye en punto de integración y encuentro en el Mercosur.

El plan identificó cinco líneas de trabajo para avanzar esta visión de ciudad: construir la Ciudad del Trabajo, la Ciudad de las Oportunidades, la Ciudad del Rio, la Ciudad de la Integración, y la Ciudad de la Creación.

Énfasis en los niños. El Plan Estratégico percibe a la ciudad como una ciudad que debe pensarse desde los más débiles, como son los niños.

Por ello plantea:

La igualdad que importa es la que importe a los niños. Lo que importa a los niños tiene que ver más bien con el acceso a espacios verdes, bibliotecas, campos deportivos, cursos de violín, y todo aquello que puede servir para el desarrollo de su potencial humano.

Entre las concreciones del municipio en este campo se hallan el Programa Crecer y el Tríptico de la infancia: Granja de la Infancia, Jardín de los Niños e Isla de los Inventos. También la creación única de los Consejos de los Niños, en donde niños elegidos por los otros niños, aconsejan, fabrican ideas e inventan en una practica de valor formador incalculable. González (2005) cuenta:

Retomemos la feliz iniciativa de los chicos del Primer Consejo de Rosario (1998) de declarar el Día del Juego y la Convivencia e instar a los sectores públicos y privados a "parar" unas horas para recordar que "jugar y convivir" son la democracia en verbo.

Tantos jugaron, participaron, debatieron, tantos lazos se actualizaron ese día de octubre que en definitiva los niños políticos de los consejos habían encontrado una de las formas de participación más poderosas y eficaz del mundo: el juego (los chicos lo saben porque es el modo en que conocen el mundo, y nosotros lo sabemos porque la historia nos lo dice, pero lo olvidamos rápidamente). 
La gestión municipal descubre en este acontecimiento una muestra de la utopía posible, una manera extraordinaria de apropiación del espacio público por los ciudadanos, una forma de creación colectiva.

Descentralización del Estado. En Rosario se fue mas lejos de lo convencional en los intentos de descentralización urbana.

No se trató simplemente de abrir oficinas de atención al ciudadano en los diversos distritos de la ciudad. Se adoptó como principio que los servicios se debían ofrecer desde el lugar más cercano al ciudadano, y se crearon Centros Municipales de Distrito. Son centros que cumplen los siguientes roles simultáneos (Riveros, 2005):

v Un centro administrativo y de servicios, que facilita la resolución de trámites y la prestación de servicios públicos.

- Un centro comunitario, que da cabida a una multiplicidad de programas y actividades-administrativas, de servicios, de desarrollo social, cultural, productivo.

v Un centro de coordinación entre las diferentes áreas municipales para ese territorio particular.

- Un centro de participación ciudadana, lugar de encuentro entre las distintas organizaciones o entidades barriales.

Presupuesto participativo. Siguió las modalidades de Porto Alegre y otros semejantes con mejoras para adecuarlo plenamente a las características de Rosario y llevarlo a cada rincón de la ciudad. A ello sumó una experiencia renovadora, el Presupuesto Participativo Joven. Los jóvenes de cada distrito eligieron representantes que en asambleas identificaron los proyectos que entendían debían formar parte del presupuesto participativo del distrito. Ello permitió agregar al presupuesto una mirada desde las inquietudes, intereses, y visión de la sociedad de los jóvenes. Al mismo tiempo esta práctica se convirtió en una escuela de desarrollo democrático de los mismos jóvenes.

En el 2004, se sumó otra mirada adicional, la de la perspectiva de género. Se adoptaron todo orden de medidas para garantizar la participación plena de las mujeres en todo el ejercicio del presupuesto participativo. Entre ellas, la mitad de los miembros del Consejo del Presupuesto debían ser mujeres.

Plan Urbano participativo. Elabora las acciones de planificación urbana por distrito con el consenso de las diversas instituciones y organizaciones de cada barrio. 
Política de Salud cogestionada. El sistema de salud de la ciudad es reconocido nacional e internacionalmente por su efectividad. La salud se convirtió en una prioridad central en Rosario. Pasó de representar menos del $8 \%$ del presupuesto municipal en 1989 , hasta el $25 \%$. La mortalidad infantil bajo de 25,9 por mil en 1988 a 11,4 en el 2003. Las consultas en hospitales se elevaron en un $108 \%$, las consultas en los Centros de Salud en un $314 \%$, niveles muy superiores al crecimiento demográfico de la ciudad.

Los pilares del sistema de excelencia de salud pública montado por el municipio han sido la descentralización y la participación.

Inspirado en concepciones de avanzada de la medicina, se propone trabajar junto con la comunidad en la prevención.

La ciudad se transformó en un municipio saludable, donde la comunidad entera esta trabajando en los grandes preventores en salud, como la protección del ambiente, la nutrición saludable, el ejercicio físico, la recreación, y la seguridad vial.

La intensidad de la relación forjada entre el municipio y la sociedad en el campo de la salud puede percibirse en el grafico retrato que hace un acreditado especialista en salud Mario Rovere (2005):

Pero en todo caso, y tal vez por mi sesgo de recursos humanos, de educación, si yo tuviera que elegir el resultado que más me impacta, diría que lo encuentro en sentir que cada vez que estoy en Rosario, que cada vez que entro en contacto con cualquier nivel de la organización, tengo la sensación de encontrarme con personas que aprenden, con equipos que aprenden, con organizaciones que aprenden, orientados por una permanente insatisfacción, por un fuerte compromiso con la población, fuentes inagotables de motivación, curiosidad, innovación y creatividad.

Gestión asociada del Estado con otros actores sociales, como las empresas, y las organizaciones de la sociedad civil.

Mecanismos participativos múltiples. Se planificó crear diversos canales para dar todas las posibilidades a la participación ciudadana, entre ellos audiencias públicas, consejos consultivos distritales, consultas populares e iniciativas populares.

Todos estas y otras direcciones de trabajo tuvieron como el eje común el desafío asumido colectivamente de construir una ciudad con rostro humano. La participación fue la constructora de esta gran concertación. Ella a su vez fue la base de legitimidad que permito al gobierno municipal hacer los grandes cambios realizados y en marcha. 


\section{Lecciones de las experiencias exitosas}

¿Qué lecciones de conjunto pueden sacarse de Porto Alegre, Villa El Salvador y Rosario que puedan apuntalar el fortalecimiento de la participación popular en la región?

Son tres experiencias bien disímiles en contextos nacionales muy diferentes. Una en un país-continente Brasil, es la experiencia de un estado municipal que abre una vía inédita en la historia del país y del continente, con un presupuesto municipal participativo, y ahora junto a el con la gobernanza solidaria local que cambia totalmente el estilo de relaciones entre Estado y sociedad.

Otra Villa El Salvador es una experiencia pura de la sociedad civil, en donde en una sociedad que ha discriminado fuertemente a sus indígenas, ellos levantan de la nada un municipio modelo cuyos logros se convierten en referencia mundial.

La tercera, Rosario, es una ciudad que adopta una dirección contra los vientos predominantes que reducían al Estado a un rol mínimo, y ayuda colectivamente a construir un municipio con políticas públicas totalmente activas, y que establece un modelo de cogestión integral con la ciudadanía.

Sin embargo a pesar de las diferencias históricas y de las especificidades hay ciertos aspectos comunes muy relevantes.

\section{Primero. La participación se mostró como una estrategia maestra para reducir la desigualdad}

En primer lugar en los tres casos el contexto era de agudas polarizaciones sociales. Brasil es uno de los países más desiguales del planeta, Perú tiene un altísimo coeficiente Gini pero además marcadas discriminaciones hacia la población indígena, Argentina se convirtió en los 90 en una sociedad totalmente inequitativa, y las políticas económicas aplicadas convirtieron en nuevos pobres a amplios sectores de las clases medias.

En esas condiciones y en el marco favorable que implicaba una lucha permanente por la profundización de la democracia en los tres países, las tres experiencias movilizaron a fondo la participación ciudadana, y ella actuó como un gran igualizador social.

Los profundos desequilibrios de poder económico, discriminaciones, y asimetría política, desaparecieron al interior de las experiencias por la integración igualitaria a través de la participación. Todos pudieron informarse, analizar, y tomar parte en decisiones claves para el destino de sus municipios. 
El resultado fue políticas democratizantes, a favor de los más débiles, que redujeron sensiblemente los desequilibrios dentro de lo que estaba al alcance de marcos municipales.

El municipio se concentró en los tres casos en generar bienes públicos como salud, educación, atención especial a los niños, espacios para microempresas, y muchos otros, que redujeron los costos de vida de los pobres, mejoraron su educación y empleabilidad, y les abrieron posibilidades de inclusión social.

Se corroboró la tesis anteriormente planteada. Cuando hay mucha desigualdad como en América Latina la región mas desigual de todas, la participación es una gran fuerza que puede corregir los sesgos de políticas marcadas por los intereses de los grupos de mayor poder, haciendo sentir el peso de las legitimas prioridades de las mayorías débiles.

Desde ya ello que funcionó con fuerza en el nivel local, tiene otra complejidad y dificultades a nivel nacional, pero el camino parece tener plena validez. Así los países más igualitarios del mundo como los nórdicos se caracterizan por la presencia de dosis inéditas de participación ciudadana.

\section{Segundo. Para movilizar la participación se necesita un proyecto político de real intención democratizadora. política, económica y social}

En los tres casos, la marcha hacia los logros tuvo que pasar por resistencias y dificultades enormes. Sólo la existencia de un proyecto político coherente, centrado en la inclusión social, la equidad, y el desarrollo pleno de la ciudadanía pudo enfrentar y superar las diversas coyunturas difíciles, sin que las experiencias naufragaran bajo su peso.

En Porto Alegre y Rosario fueron los proyectos políticos de partidos de clara tendencia reformadora, en Villa El Salvador el proyecto social-humanista de una comunidad organizada. La consistencia de esos proyectos fue un pilar en la continuidad de las experiencias que cumplen ya 17 años en Porto Alegre, y Rosario, y 35 en Villa El Salvador.

\section{Tercero. Las experiencias de participación democratizante se transforman de proyectos de un partido o sector en proyectos colectivos}

En Porto Alegre la ciudad hizo suyo el Presupuesto Municipal Participativo. Sus beneficios eran para todos, y para la ciudad en su conjunto. A tal punto 
que reiteró su apoyo en tres oportunidades al partido que inició el proyecto, y finalmente en la última cuando dio su votación a otras corrientes partidarias las mismas asumieron como suyo el presupuesto participativo, y trataron de profundizar las vías que había instalado.

En Villa El Salvador se sucedieron alcaldes de diverso signo político, pero el carácter básico del proyecto permaneció inalterado.

En Rosario como el partido que llevó adelante el proyecto era totalmente minoritario a nivel nacional se dio la paradoja que la misma población votaba para presidente del país a los candidatos de partidos mayoritarios y consistentemente durante tres periodos para intendente de la ciudad al partido que condujo el proyecto de renovación integral de la ciudad.

\section{Cuarto. Es fundamental el capital cultural y social existente}

Los recursos financieros son muy importantes para montar experiencias avanzadas. También contar con infraestructura, capital fijo, recursos naturales, $\mathrm{y}$ otros bienes de capital. Pero hay una forma de capital que es la decisiva, y que fue la que inclino la balanza a favor del éxito de la experiencia en estos casos, el capital cultural y social de la comunidad.

En Porto Alegre la experiencia no surgió de la nada, sino de un tejido social muy rico en experiencias asociativas. Lo describe Navarro (1998):

La historia asociativa de Porto Alegre se asemeja bastante a la de Rio Grande do Sul, sin duda el estado de la Federación que ostenta la mayor vitalidad organizativa, inclusive en sus áreas rurales. Ya en 1956 un decreto municipal abrió las puertas a diversos consejos y asociaciones comunitarias, posteriormente hermanadas en la Federación Riograndense de las Asociaciones Comunitarias y de Barrios (Fracab), fundada en 1959, y con una activa actuación, particularmente entre fines de los años setenta y mediados de la década siguiente.

En 1979, la Federación ya contaba con 65 asociaciones afiliadas, sólo en Porto Alegre. En 1983 se fundó la Unión de las Asociaciones de Vecinos de Porto Alegre (Uampa), un consorcio de organizaciones fuertemente politizado, que reflejaba la liberalización política del país durante la primera parte de esa década. La Unión estuvo intensamente involucrada en varias áreas de conflicto y de disputas, tales como viviendas populares, acceso a la educación, oferta de servicios de salud en los barrios más pobres, y derechos humanos, entre otras de menor envergadura. De acuerdo con diversas estimaciones, existirían actualmente en Porto Alegre alrededor de 500 asociaciones comunitarias, cifra que aún pudiendo ser algo exagerada, ubica a la ciudad como una de las más dinámicas del país, en términos asociativos. 
En Villa El Salvador los indígenas que bajaron de los Andes peruanos y crearon Villa carecían de todo bien material pero tenían detrás suyo miles de años de cultura indígena, en la que las tradiciones asociativas eran de una fuerza singular. Venían de viejas civilizaciones que habían creado instituciones modelos con el Ayllu peruano, y toda una cultura de la propiedad comunal. En ellas se apoyaron, e incluso en algunos de sus notables desarrollos tecnológicos como las lagunas de oxidación de los Incas que permitían transformar los desechos en abonos.

En Rosario la ciudad tenía una tradición social avanzada. Por muchos años a pesar de las diversas viscitudes históricas los idearios sociales habían tenido fuerte peso en la población, y la utopía social estaba muy anclada en su cultura.

\section{Quinto. Es decisivo el modelo organizacional y la calidad de la gerencia social}

Probablemente aun cuando se hubieran dado componentes como los anteriores, voluntad política, un proyecto, capital social, interés colectivos, las experiencias podían haber fracasado sino hubiera habido un modelo organizativo apropiado y gerencia social de excelencia. Como ha señalado Sulbrandt (2006) la verdadera política no es la que esta en el papel, sino la post-gerencia, la que queda después de la implementación. Las mejores intenciones de participación si luego se opta por estilos organizacionales burocráticos, o paternalistas, pueden transformarse en todo lo contrario de lo que se quería. Los propósitos más genuinos de concertar con la comunidad y consultarla, pueden estrellarse si se usan métodos de gestión verticales, y que compartimentalizan.

En los tres casos hubo un gran esfuerzo de creación de modelos ad hoc que rompían con todo lo existente, y que demostraron ser los acertados.

En Porto Alegre una sofisticada y compleja armazón de reuniones, asambleas, ciclos de programación, ciclos de rendición de cuentas que convirtieron a la participación colectiva en el presupuesto en una realidad factible.

En Villa El Salvador un funcionamiento de democracia directa a través de asambleas, unidades organizacionales múltiples, liderazgo rotativo, información colectiva continua, que generaron la integración a la experiencia de la gran mayoría de la comunidad.

En Rosario un entramado de consultas, y deliberaciones entre Estado y sociedad a todos los niveles para numerosísimos aspectos, que generaron redes, espacios de dialogo, reconocimiento mutuo, y un gran clima de confianza. 


\section{Sexto. Lo más importante es el proceso democratizador en sí}

En todos los casos los logros son formidables. Mejoro drásticamente el nivel de vida de la gente, de las familias, y la calidad de la ciudad. Todo ello dentro de las restricciones ya enfatizadas anteriormente de una ciudad dentro de un país. Sin embargo lo más importante fueron los aprendizajes, experiencias, y empoderamiento colectivo de la sociedad y fundamentalmente de sus sectores excluidos como consecuencia de la apelación sincera, real, y abierta a la participación y la creación de condiciones propicias para ello.

En los tres casos, creció muy fuertemente el capital social de la sociedad. Las diferentes dimensiones del capital social: la confianza, la capacidad de asociatividad, la conciencia cívica, los valores éticos positivos, se multiplicaron.

La comunidad es ahora mucho mas consciente, articulada, informada, y su autoestima se ha fortalecido significativamente. Esta en condiciones de sostener las experiencias como lo ha hecho, y también de insertarse de modo activo en el escenario nacional como un actor activo a favor de los cambios requeridos para que la pobreza persistente, y los altísimos niveles de desigualdad sean enfrentados adecuadamente.

\section{6. ¿Por qué no avanza más la participación?}

Las experiencias exitosas analizadas indican que la participación es viable en América Latina, cuando se dan una serie de condiciones. Pero cabe preguntarse, porque a pesar de los procesos democratizantes en marcha, el amplio consenso social que hay sobre ella, la unanimidad en el discurso político, los numerosos intentos de leyes y normas para propulsarla, y los muy concretos beneficios que aporta a la lucha por el desarrollo, porque no avanza mas rápida y sostenidamente.

Es posible detectar que en el pensamiento predominante en las elites de la región que en sociedades tan asimétricas han tenido incidencia decisiva en las decisiones hay desde ya con excepciones, importantes resistencias. Por otra parte ese pensamiento permea con frecuencia a amplios sectores de la población que tienden a absorber la mirada de mundo que ofrece. Hay una cultura antiparticipatoria fuertemente subyacente en la región a pesar de todos los otros avances. Algunos de sus núcleos esenciales son los que se presentan esquemáticamente a continuación (Kliksberg, 2006). 


\section{El pensamiento único}

La idea de que en economía hay un solo camino, las políticas ortodoxas rígidas, fue asumida por gran parte de las elites de la región en los 80 y 90, y se expresó en políticas económicas concretas, que ya han sido juzgadas por los hechos.

El crecimiento que ofrecían fue muy débil, el supuesto "derrame" que sacaría de la pobreza a los pobres no funcionó y la pobreza aumentó, la industria y el comercio nacional fueron minimizados en el proceso, el Estado semidesarticulado, se perdió capacidad de decisión autónoma en economía, y la desigualdad estalló. La población reaccionó con la ola de cambios políticos en muchos casos tumultuosos que se produjeron en los últimos años.

El pensamiento único no sólo preveía recetas económicas, tras el hay subyacente toda una visión de la sociedad. Se la percibe como una sociedad básicamente individualista, donde las personas ante todo son homus economicus que luchan entre sí en el mercado por ganar terreno, cuya orientación central es maximizar el lucro, donde como fuera resumido siglos antes por los antecesores del neoliberalismo "el egoísmo privado conducirá al bienestar colectivo".

En esa visión de sociedad la cooperación, la solidaridad, y la participación no tienen lugar mayor. Son antiéticas con los incentivos de mercado que se procura impulsar. Son vistas como obstáculos o rigideces porque entorpecen la lucha por la supervivencia de los más aptos que la concepción general propicia.

La red social en la que se piensa es una de productores y consumidores atomizados enfocados al lucro, orientados a superar al rival, que solo se asocian en combinaciones dirigidas a oligopolizar, monopolizar, o pelear contra las combinaciones rivales en mejores condiciones. No hay en general afectos sino intereses que se negocian.

Por otra parte esa sociedad atomizada es el espacio social ideal para ser objeto pasivo de políticas muy duras que generan un grupo limitado de ganadores, y una multitud de perdedores. En este tejido social débil y deshecho será difícil que los perdedores puedan organizarse y resistirlas.

La visión economicista, y atomicista de la sociedad, excluye la participación, que por el contrario propone pasar de la atomización a la integración de esfuerzos, del egoísmo personal a la cooperación, y de la lucha despiadada a las sinergias.

\section{El clientelismo}

Sectores significativos de las elites han desarrollado todo un aparato elaborado de prácticas clientelistas que opera en un ciclo político que se ha repetido una y otra vez. 
Las aplican en primer lugar para atraer el apoyo de los sectores con menos información y más desorientados de la sociedad hacia propuestas ilusorias, o ambiguas, de neto sello demagógico. Son así típicas las consignas que han utilizado en el campo de la seguridad pública presentándolo como un simple problema policial que se resuelve con un hombre de mano dura, o en el de la pobreza prometiendo metas generales, sin ingresar en planes concretos.

Después las utilizan para sostener gestiones de gobierno que no producían mejoras reales en la vida de la población. El "circo" tendía a reemplazar a los hechos. Por último han apelado casi con desesperación al clientelismo bajo todas sus formas desde las más primarias como la compra de votos, hasta otras mas sofisticadas como la captación de líderes populares, o la conformación de intereses creados de todo orden, para tratar de perpetuar su poder.

El clientelismo tiene uno de sus enemigos más formidables en la participación genuina de la población. Es todo lo contrario de lo anterior, significa la comunidad pensando y decidiendo sola que es lo que más le conviene. Tratando de no ser utilizada para agendas que no son la suya, y no conformándose con meras promesas, sino manteniendo un control social permanente sobre la implementación de las políticas.

Las prácticas clientelares, han obstaculizado, por todas las formas posibles el desarrollo de formas reales de participación. Son directamente contradictorias con la imposición encubierta de la voluntad de un grupo reducido sobre las mayorías para sus propios propósitos, que significa el clientelismo.

\section{LA VISIÓN TECNOCRÁTICA}

Con frecuencia en la región liderazgos políticos avanzados recogiendo el mensaje de la ciudadanía han dictado leyes o puesto en marcha políticas destinadas a basarse en la participación, especialmente en el campo social. Sin embargo, en diversos casos la implementación de los procesos respectivos ha caído en manos de grupos que leen la realidad desde una perspectiva unilateralmente tecnocrática.

Para los "tecnócratas puros" la participación es básicamente una dilación. Ellos creen que podrían llevar adelante los mismos programas sin las "perdidas de tiempo" que implica la consulta y la deliberación continua con la comunidad.

Por otra parte, ella significa el riesgo de que su visión tecnocrática de como deben hacerse las cosas pueda ser testada por las comunidades pobres, $\mathrm{y}$ puesta en tela de juicio lo que no están dispuestos a aceptar. 
La combinación de purismo tecnocrático y soberbia, de los que creen que saben, se combina además con la concepción de que la participación es un proceso organizativo más. Bastaría planificarlo, establecer procedimientos y rutinas, fijar manuales de normas y debería funcionar.

Desde ya que se requiere utilizar el mejor instrumental técnico disponible pero ello no basta porque es un proceso de naturaleza social compleja donde hay que cambiar actitudes, correlaciones de poder, lograr el ownership que las comunidades lo hagan realmente suyo, y otros cambios estructurales.

Los arreglos técnicos no bastan. Se requiere desde su inicio el involucramiento de los actores, su sentimiento de que el proceso es real y no declamativo, su percepción de que efectivamente podrán incidir, su visión de que producirá beneficios reales a la comunidad, y su capacitación para que puedan usar adecuadamente los canales pensados en conjunto.

Eso es por ejemplo lo que sucedió en Porto Alegre. Tras la desconfianza profunda de los dos primeros años, con limitados resultados, cuando la comunidad advirtió luego que a través del presupuesto municipal participativo podía influir de verdad, y cambiar efectivamente las asignaciones de recursos, entonces participó.

\section{La desvalorización de los desfavorecidos}

Tras la resistencia a la participación en las elites y los tecnócratas existe en muchos casos, algo aun más profundo, que es la persistencia de una cultura discriminatoria.

Perciben a los sectores sociales excluidos, o en pobreza, desde el prejuicio. Las encuestas lo han detectado con frecuencia en América Latina respecto a los indígenas, la población de color, y otros grupos minoritarios empobrecidos. También respecto a la propia figura del pobre. En muchos casos, es la actitud con que se percibe a la mujer desde "el machismo" de tanta vigencia en la región.

Si se parte de la descalificación silenciosa del otro por ser indígena, negro, o mujer pobre, es difícil que se puedan organizar las condiciones para un proceso de participación real.

Tácitamente el pensamiento prevalente en los planificadores de la participación será el que en definitiva estará destinada al fracaso, por las supuestas carencias congénitas de la población a la que se invita a participar. Tras la reiterada descalificación porque "no tienen educación" se oculta en definitiva un prejuicio más raigal sobre su misma condición humana que los inhabilitaría para participar como iguales. 
En el mejor de los casos deberían ser tutoreados muy estrictamente para limitar sus "disfuncionalidades naturales".

Allí se cumple la conocida ley sociología de la "profecía que se autorealiza". Las comunidades desfavorecidas son muy sensibles al prejuicio, lo intuyen claramente, se pone en cuestión su misma autoestima, sienten que su cultura y sus personas son desvalorizadas, además sienten que en definitiva que son manipulados porque no se cree realmente en ellos y su potencial de avance.

Ingresan entonces en simulaciones de participación pero sin comprometerse, o se rebelan abiertamente.

En resumen, se crean condiciones como para que efectivamente no participen y después finalmente el ciclo se cerrara cuando los directores de las experiencias les adjudiquen la culpa por el fracaso de la participación.

La profecía se habrá cumplido.

\section{Es el poder amigo, el poder}

En la excelente y rigurosa evaluación que Navarro (2005) realizó de la experiencia de Porto Alegre, se autoplanteó una pregunta central: ¿la experiencia es trasplantable a otras realidades? Su respuesta es:

\footnotetext{
El requisito previo más importante y decisivo que se debe tener en cuenta para emprender un proceso participativo social, es que las autoridades locales deben tener una fuerte voluntad política para compartir con sus electores una proporción considerable del poder que detentan. En el papel, esta disposición política parece lógica y muy atractiva para aquellos que detentan el poder. Sin embargo en la práctica, es una faceta rara de la política. No convencidos por lo general, quienes detentan el poder aceptan, cuando mucho, la participación consultiva y, en realidad, no comparten el proceso decisorio.
}

Eso es efectivamente lo que sucedió en Porto Alegre, Villa El Salvador, Rosario, y otros casos.

En realidad no se trata de compartir, porque el poder en una democracia solo pertenece a la comunidad, ella selecciona representantes para que lo ejerzan. Si los representantes abren los canales que se abrieron en esas experiencias el lazo representados-representantes se mantiene activo todo el tiempo, y todo el proceso es pleno en contenidos democratizantes.

Si por el contrario quienes han recibido el poder, quieren utilizarlo para fines que pueden alejarse o ser directamente conflictivos con los de la comunidad, o desean sesgarlos a los intereses de sectores elíticos, la 
participación es para ellos un enemigo formidable. No solo porque puede disputarles su agenda, sino porque es una especie de "entrometido no deseado" permanente en su gestión con su potencial de fiscalización social, y pedido continuo de rendición de cuentas.

La democracia ha evolucionado en el planeta desde sus formas puramente electorales hasta modelos cada vez más activos. Hoy se distingue entre democracias de alta intensidad donde los ciudadanos participan vigorosamente por múltiples canales, democracias de mediana intensidad con participaciones significativas pero acotadas, y democracias de baja intensidad donde solo hay una delegación electoral cada tantos años.

Los líderes que aspiren a una democracia de alta intensidad verán como un aliado a la participación, los que deseen una democracia más formal que real la verán como un adversario. Ello sucede a diario en América Latina.

Se podría pensar que quienes comparten el poder a través de la participación lo pierden en parte, mientras que los que la rehuyen tienen mas poder. Paradojalmente, las experiencias de la región han demostrado lo contrario. Quienes lo comparten logran que el poder total disponible para realizar cambios importantes aumente, y el poder se haga sustentable. En Porto Alegre el partido que introdujo el presupuesto participativo ganó varios periodos electorales sucesivos y finalmente perdió ante un frente cuya propuesta era profundizar aun más la participación. En Rosario, el partido proparticipación se ha impuesto por amplio margen en tres elecciones sucesivas.

Por lo contrario quienes se apoderan del poder y cierran puertas a la participación, tienen un potencial enorme de conflicto con la población. En cuanto comienzan a incumplir las expectativas y el mandato, su credibilidad y legitimidad se erosiona, y el poder disponible se reduce. Crece la ingobernabilidad. Ello ha sucedido en la última década con frecuencia en la región.

¿Por qué no progresa más rápido la participación?. La acción conjunta del pensamiento único, el clientelismo, la visión tecnocrática, las culturas de la discriminación, y la tentación del apoderamiento del poder, han sido algunas de las concepciones que hechas suyas por sectores de elite, y tecnocráticos, por lideres cooptados para ellas, y asumidas inconscientemente por algunos sectores de la población, han construido una muralla para las mejores intenciones participatorias.

\section{Pre requisitos para una participación efectiva en América Latina}

¿Cuáles son las condiciones para que puedan enfrentarse la "muralla" y en general dar impulso sostenido a la participación en América Latina? 
Osmani (2006) plantea agudamente que hay dos tendencias en la literatura internacional al respecto. Una enfatiza que el tema no es técnico sino la creación de "poderes equilibradores", de mecanismos que reduzcan las "ventajas de poder de los usuales actores sociales poderosos".

La otra tendencia resalta la importancia que se realicen todos los derechos cívico-políticos porque no se podría crear el poder equilibrador necesario sin derechos como el de libre expresión, información, igual acceso a la justicia y otros. También se resalta que los pobres deben tener un mínimo de seguridad económica para que pueda esperarse se involucren en actividades orientadas a la construcción de poderes equilibradores.

En el caso de América Latina claramente cuanto más progreso haya en el plano de la democratización y sus contenidos de igualación de derechos cívico-políticos, más factible es promover la participación. Por otra parte también ella se beneficiaría sobremanera de que los pobres tengan aseguradas sus necesidades básicas.

¿Significa ello que deba esperarse a reunir estas condiciones para entonces hablar de participación en la región?

Si tratamos de aprender de las experiencias latinoamericanas, las más pujantes no han esperado esas ventajas absolutamente útiles, pero en muchos casos distantes en el tiempo.

Las comunidades de base que las impulsaron en casi todos los casos directa o indirectamente, se autopercibieron como sujeto activo que podía cambiar la realidad, y hicieron los máximos esfuerzos en autoorganizarse. A veces tuvieron la ayuda de organizaciones de la sociedad civil, otras no. En muchos casos su desconfianza inicial del Estado fue importante, y las estructuras burocráticas tradicionales tampoco tuvieron mayor interés en ellas.

En el proceso de autoorganización generaron participación a su interior, el proceso tuvo realizaciones y ellas lo retroalimentaron, fueron fortificándolo, y al asumir niveles crecientes de conciencia comunitaria, y de su poder de influir, lucharon por ampliar sus derechos políticos, y por obtener apoyos para mejorar sus condiciones económicas.

La lección en América Latina de experiencias de participación en escala importantes como la Confederación de Nacionalidades Indígenas del Ecuador, las Escuelas Educo de campesinos pobres en El Salvador, las madres del Vaso de Leche en Perú, Villa El Salvador en el Perú, y otras, es que lo más importante de todo es como se destacó anteriormente el mismo proceso de autoorganizarse y comenzar a participar colectivamente. En el los pobres readquieren la estima perdida, revalorizan su cultura, y recuperan confianza en sus fuerzas. 
Franco (1992), prominente sociólogo peruano, y agudo analista de Villa El Salvador explica que es típico que cuando se le preguntaba a un habitante del municipio de donde era, no contestaba mencionando el pequeño poblado de los Andes donde había nacido, sino decía "soy de Villa". Estaban diciendo que ellos habían creado Villa una experiencia reconocida mundialmente pero en el camino Villa los había recreado a ellos.

El estudio en gran escala del Banco Mundial sobre 60 mil pobres de 60 países "Las voces de los pobres" (Narayan, 2000) llega a conclusiones similares. Cuando se les preguntó a los pobres sobre en que medida creían en diversas organizaciones de la sociedad, la credibilidad de la mayor parte de las organizaciones era muy baja. En segundo lugar de su lista de credibilidad figuraban las iglesias porque trabajan junto a ellos por sus problemas, y en primer lugar las organizaciones de la propia comunidad.

Era comprensible antes en el estudio explican que lo que más le duele de la pobreza, es la desvalorización. El hecho de ser mirados, y tratados por los demás como personas de una categoría inferior, como una especie de subhumanos. En las organizaciones de la propia comunidad, recobran su autoestima individual y colectiva.

Por eso en Villa describe Franco:

cuando se asiste con alguna frecuencia a reuniones de pobladores, y se conversa con los fundadores de la comunidad o sus dirigentes no resulta difícil advertir expresiones recurrentes de autoconfianza colectiva, certidumbres sobre su disposición de una poder organizado, una cierta creencia en las capacidades de la comunidad para proponerse objetivos, y unirse para su logro.

¿La idea de que la participación es en si misma un precondición para la participación porque genera en el proceso los incentivos e impulsos será sólo aplicable a nivel de experiencias acotadas?

No parece porque el mismo camino parecen haber seguido algunos de los grandes cambios políticos que se observan en la región. Las 14 presidencias que fueron interrumpidas entre 1993 y el 2005 lo fueron bajo múltiples formas por movimientos de participación creciente de la ciudadanía. En algunos casos esos movimientos crecieron en el mismo proceso y finalmente lograron asumir gran parte del poder como sucedió con la población indígena en Bolivia, y con el ascenso político de la población indígena en El Ecuador.

Por ende aparece como una primera condición básica para la participación en América Latina, la movilización de los mismos pobres. Ella a su vez esa supeditada a una segunda condición. Esa movilización no se produjo en ningún 
lugar en el vacío. Tiene que haber un importante capital cultural y social previo favorable a ella.

Como ya se refirió Porto Alegre tiene ese capital. Allí nacieron algunos de los primeros movimientos ambientalistas del Brasil, se ha destacado como ciudad amiga de los niños, tiene una larga tradición de asociativismo. También lo tienen los aymaras que son la base de los movimientos sociales que ahora son poder en Bolivia. Es una de las civilizaciones más antiguas del género humano. Tiene como la incaica, la quechua, y otras de los Andes peruanos una profunda sabiduría de vida. Practica una relación armoniosa con la naturaleza, tiene valores procooperación, exalta la idea de la propiedad comunal.

Bajo diversas formas y contenidos pueden encontrarse bases significativas de confianza intracomunitaria, capacidad de asociatividad, conciencia cívica, cultivo de la familia, valores éticos aplicados en la vida cotidiana, es decir de las principales dimensiones del capital social en las más significativas experiencias participativas de la región.

América Latina tiene raíces importantes de este orden producto de sus civilizaciones indígenas, sus gestas libertarias, sus migraciones europeas portadoras de valores e ideales. Ella ha posibilitado la existencia de una dinámica sociedad civil, el desarrollo del voluntariado, una creación cultural de gran envergadura. La literatura latinoamericana se ha convertido en una de las más visitadas del planeta porque refleja esta riqueza cultural.

En los periodos más duros recientes, como la noche negra de las horrorosas dictaduras militares del Cono Sur, en los 70, a pesar de que destruyeron todas las formas de participación y trataron de atomizar a la sociedad, encontraron una resistencia cultural y social excepcional en esa sociedad civil. La protesta se expreso a través del teatro, las revistas humorísticas, el arte y creativas manifestaciones emanadas del capital social.

Junto a poner en marcha la participación, y al capital social, otra precondición fundamental es como se menciono que haya un liderazgo político que tenga un proyecto nacional inclusivo, para todos.

Si el proyecto como lo fue en los 90, es de supuesta modernización no importa los costos en términos de exclusión y dolarización, la participación será un estorbo. Ese proyecto requiere concentración del poder, y no equilibrios de poder.

Si el proyecto como aparece en muchos países al impulso de los reclamos ciudadanos actuales es de crecimiento compartido, desarrollo sostenible, inclusión universal, la participación es una vía regia para crear bases sociales firmes de apoyo al mismo.

Otra precondición es contar con los instrumentos organizacionales para hacer real la participación. Es necesario generar instituciones y modelos 
organizacionales acordes a ella. Que refuercen la transversalidad, y las relaciones horizontales, en lugar del verticalismo. Que afiancen el trabajo en equipo en lugar de las figuras providenciales. Hoy gran parte de la gerencia del siglo XXI va en esa dirección en diversos ámbitos, porque se ha verificado una y otra vez que las organizaciones en donde hay involucramiento son las únicas que pueden transformarse en organizaciones que aprenden, son las de mayores niveles de productividad, son las más aptas para la innovación tecnológica.

Muchas veces en la región se ha tratado de hacer participación utilizando modelos organizaciones piramidales cuyo contenido es justamente el opuesto.

Otro punto es asegurar la representatividad en el proceso participatorio. Los mecanismos de selección de delegados, representantes y líderes deben ser transparentes, confiables y de la mayor calidad.

Una característica central de un modelo realmente participatorio será que en sí mismo deberá ser una escuela de aprendizaje. Deberá nutrirse con capacitación permanente para hacerlo cada vez mejor partiendo de los errores y aprendizajes cotidianos.

Otra precondición es que la participación sea vista no sólo en su dimensión política, económica y social, sino en lo que implica éticamente. Es ante todo no una concesión, sino un derecho fundamental del ser humano que debería ser respetado en toda sociedad existente. Hace a su misma dignidad humana. Se requiere que la sociedad en su conjunto asuma la participación como uno de sus valores éticos. Ese es el rango que tiene en alguna de las sociedades más avanzadas del planeta como las nórdicas.

Se requiere por último en esta nomina desde ya incompleta una gran concertación social para movilizar la participación. No debe darse por tacita o asegurada, ni tomarse como una bandera sectorial, es una causa que va a permitir movilizar al máximo el potencial productivo, cultural y humano de toda la sociedad. Esa liberación del potencial de la sociedad es en definitiva un objetivo final de cualquier sociedad, y la estrategia más poderosa para hacerla progresar, insertarla competitivamente en las nuevas realidades económicas, y asegurar la sostenbilidad de su desarrollo.

\section{Perspectivas de la participación en la región}

América Latina requiere urgentemente de "poderes reequilibradores". En una región de tan elevadas desigualdades, difícilmente se logre reducir de modo efectivo la pobreza, y obtener un desarrollo integrado sino se reequilibra el acceso al poder para que el mismo asuma como una prioridad central el enfrentamiento de la pobreza y el acceso a oportunidades para todos. 
Hoy eso no es una proposición de un grupo de personas de buenos deseos, sino que es una exigencia de las grandes mayorías, que reclaman por vía de la democracia, el único modelo en que América Latina cree, un desarrollo más sostenible y equitativo.

La exigencia es apremiante. Según los resultados del último LatinBarómetro (2005) "Un 75\% de los trabajadores de la región están preocupados de quedar sin trabajo en los próximos 12 meses". Ese porcentaje no cambia desde el 2002 a pesar del crecimiento económico de los últimos dos años. Por otra parta la inquietud es muy fundada. En un 59\% de los hogares una persona ha estado desempleada en los últimos 12 meses.

La participación es como se ha visto en este trabajo una gran promesa de reequilibramiento social, y de desarrollo.

La región cuenta con precondiciones favorables para que la participación despegue. Tiene significativas experiencias exitosas, un amplio capital social, hay nuevos liderazgos políticos con proyectos inclusivos. Sin embargo para evitar el peso de pensamiento único, de la tradición de prácticas clientelares, del tecnocratismo, de la tendencia a desvalorizar a los desfavorecidos, y de las simples resistencia a democratizar el poder, será necesario que la participación se incorpore a la gran agenda de las luchas populares.

También que se avance en la estructuración de nuevos diseños organizacionales y herramientas de acción que puedan dar sólido piso organizacional a la implementación de los proyectos participatorios con frecuencia, la región ha hecho en este campo "más de lo mismo" cayendo en errores reiterados. Tiene que innovar, y aprender de la gerencia social de excelencia que generaron Porto Alegre, Villa, Rosario, y muchas otras experiencias.

Por último es imprescindible recolocar éticamente esta lucha. Es la lucha por un derecho humano central. Hace a la naturaleza del ser humano. Lo veía con claridad Juan XXIII cuando en Mater et Magistra (1961) decía que "en la naturaleza de los hombres se halla involucrada la exigencia de que en el desenvolvimiento de su actividad productora tengan posibilidad de empeñar la propia responsabilidad y perfeccionar el propio ser".

\section{Referencias bibliográficas}

BANCO MUNDIAL. Desigualdad en América Latina y el Caribe: ¿ruptura con la historia? Washington, DC: Banco Mundial, 2003.

BUSATTO, C. A experiência de participação democrática em Porto Alegre e a governança solidária local. Porto Alegre: Inédito, 2006. 
CEPAL (Comisión Económica para América Latina y el Caribe). América Latina: proyecciones de población urbana y rural, 1970-2025. Boletín Demográfico, Santiago de Chile, n. 63 (LC/G2052-P), ene. 1999.

Panorama social de América Latina 2002-2003, 2003.

2005.

. Objetivos de desarrollo del milenio. Una mirada desde América Latina y el Caribe.

CUNILL GRAU, N. La transparencia en la gestión pública. ¿Cómo construirle viabilidad? In: MEZONES, F. (Ed.). Transparencia en la gestión pública: ideas y experiencias para su visibilidad. Guatemala: BID, 2006.

DE SOUZA, U. La experiencia de Porto Alegre. Demopunk: Web, 1998.

DEININGER, Klaus; OLINTO, Pedro. Asset distribution, inequality and growth. Washington, DC: The World Bank, 2002. (World Bank Policy Research Paper, 2375).

FRANCO, C. Imágenes de Villa El Salvador. In: KLIKSBERG, B. (Comp.). ¿Cómo enfrentar la pobreza? Aportes para la acción. Buenos Aires: Grupo Editor Latinoamericano, 1992.

GENRO, T. El presupuesto participativo y el Estado. In: KLIKSBERG, B. (Comp.). La agenda ética pendiente de América Latina. Buenos Aires: Fondo de Cultura Económica, BID, 2005.

GONZÁLES, C. Una ciudad con ojos de niño. In: ROSARIO, PNUD. Políticas para la gobernabilidad. 2005.

INSTITUTO DE SERVICIO GLOBAL. Voluntariado juvenil y servicio cívico en América Latina y el Caribe: una posible estrategia del desarrollo económico y social. Antecedentes para una agenda de investigación. St. Louis: Centro para el Desarrollo Social, mar. 2004.

JON-SUNG,Y.; KHAGRAM, S. Inequality and corruption. John F. Kennedy School of Government. Harvard University, 2004. (Faculty Research Working Papers Series).

JUAN XXIII. Carta Encíclica Mater et Magistra. Buenos Aires: Librería Católica Acción, 1961.

KLIKSBERG, B. Hacia una economía con rostro humano. 9. ed. Buenos Aires: Fondo de Cultura Económica, 2004.

. ¿Cómo poner en marcha la participación? Seis tesis no convencionales. In:

Más ética, más desarrollo. 8. ed. Buenos Aires: Editorial Temas, 2006.

LATINBARÓMETRO. Encuesta Latinbarómetro 2001. Respuesta a la pregunta; ¿usted piensa que la distribución del ingreso es muy justa, o injusta? 2001.

Informe 1995-2005. Santiago de Chile, 2005.

NARAYAN, D. et al. Voices of the poor. Washington: World Bank, 2000.

RaP Rio de Janeiro 41(3):537-81, Maio/Jun. 2007 
NAVARRO, Z. La democracia afirmativa y el desarrollo redistributivo: el caso del presupuesto participativo en Porto Alegre, Brasil (1989-98). In: CALDERA, A.; JARQUÍN, E. Programas sociales, pobreza y participación ciudadana. BID, 1998.

. Presupuesto participativo en Porto Alegre, Brasil. In: LICHA, I. (Ed.). Ciudadanía activa. Gestión de presupuestos locales en Asia Oriental y América Latina. BID, 2005.

ORGANIZACIÓN IBEROAMERICANA DE LA JUVENTUD. La juventud en Iberoamérica: tendencias y urgencias. Santiago: Cepal, 2004.

OSMANI, S. R. DTCD, World Public Sector Report. 2007. United Nations, 2006.

PNUD. Informe sobre desarrollo humano. Nova York, 1993.

RIVEROS, H. Las condiciones de gobernabilidad de la experiencia Rosario. In: ROSARIO, PNUD. Políticas para la gobernabilidad. 2005.

ROSARIO, PNUD. Políticas para la gobernabilidad. Argentina, 2005.

ROVERE, Mario. Una ciudad modelo en salud pública. Aportes a la construcción de una gobernabilidad democrática. Experiencia Rosario. Políticas para la gobernabilidad. 2005.

SALAMON, L. M.; SOKOLOWSKI, S. W.; LIST, R. Global civil society. An overview. Johns Hopkins University, Institute for Policy Studies, Center for Civil Society Studies. 2003.

SEN, A. ¿Qué impacto puede tener la ética? In: KLIKSBERG, B. (Comp.). Etica y desarrollo. La relación marginada. Buenos Aires: El Ateneo, 2002.

SULBRANDT, J. Formas organizacionales que facilitan la entrega de servicios sociales. Indes: BID, 2006.

UNITED NATIONS. The inequality predicament: report on the world social situation 2005. New York: Desa, 2005.

VILLA EL SALVADOR. Plan integral de desarrollo de Villa El Salvador al 2021. Jun. 2006.

ZAPATA, A. V. Entrevista a Michel Azcueta. In: Sociedad y poder local. La Comunidad de Villa El Salvador 1971-1996. Lima: Centre for Development Research and Promotion (Desco), 1996. 